\title{
Update on noninvasive imaging of right ventricle dysfunction in pulmonary hypertension
}

\author{
Uyen Truong ${ }^{1}$, Katharina Meinel ${ }^{2}$, Francois Haddad ${ }^{3}$, Martin Koestenberger ${ }^{2}$, Jørn Carlsen ${ }^{4,5}$, \\ Dunbar Ivy ${ }^{6}$, Pei-Ni Jone ${ }^{6} \wedge$
}

${ }^{1}$ Division of Pediatric Cardiology, Children's Hospital of Richmond, Virginia Commonwealth University, Richmond, Virginia, USA; ${ }^{2}$ Division of Pediatric Cardiology, Medical University of Graz, Graz, Austria; ${ }^{3}$ Division of Cardiovascular Medicine, Stanford University School of Medicine, Stanford, California, USA; ${ }^{4}$ Department of Cardiology, Copenhagen University Hospital, Rigshospitalet, Copenhagen, Denmark; ${ }^{5}$ Department of Clinical Medicine, Faculty of Health and Medical Sciences, University of Copenhagen, Copenhagen, Denmark; ${ }^{6}$ Division of Pediatric Cardiology, Children's Hospital Colorado, University of Colorado School of Medicine, Aurora, Colorado, USA

Contributions: (I) Conception and design: U Truong, K Meinel, M Koestenberger, D Ivy, PN Jone; (II) Administrative support: D Ivy, J Carlsen, M Koestenberger, F Haddad; (III) Provision of study materials or patients: All authors; (IV) Collection and assembly of data: All authors; (V) Data analysis and interpretation: All authors; (VI) Manuscript writing: All authors; (VII) Final approval of manuscript: All authors.

Correspondence to: Pei-Ni Jone, MD. Division of Pediatric Cardiology, Children's Hospital Colorado, University of Colorado School of Medicine, 13123 East 16th Avenue, B100, Aurora, Colorado 80045, USA. Email: pei-ni.jone@childrenscolorado.org

\begin{abstract}
Pulmonary hypertension $(\mathrm{PH})$ is a progressive disease affecting patients across the life span. The pathophysiology primarily involves the pulmonary vasculature and right ventricle (RV), but eventually affects the left ventricular (LV) function as well. Safe, accurate imaging modalities are critical for diagnosis, serial monitoring, and tailored therapy. While cardiac catheterization remains the conventional modality for establishing diagnosis and serial monitoring, noninvasive imaging has gained considerable momentum in providing accurate assessment of the entire RV-pulmonary axis. In this state-of-the-art review, we will discuss the most recent developments in echocardiography, magnetic resonance imaging, and computed tomography in $\mathrm{PH}$ evaluation from pediatric to adult population.
\end{abstract}

Keywords: Pulmonary hypertension (PH); echocardiography; cardiac magnetic resonance imaging; cardiac tomography imaging

Submitted Feb 23, 2020. Accepted for publication Apr 20, 2020.

doi: $10.21037 / \mathrm{cdt}-20-272$

View this article at: http://dx.doi.org/10.21037/cdt-20-272

\section{Introduction}

Pulmonary hypertension $(\mathrm{PH})$ is associated with high morbidity and mortality. It is a disease that results in high pressure load onto the right ventricle (RV). When the RV is faced with high afterload, it hypertrophies in response to the high pressure, remodels and eventually dilates $(1,2)$. RV failure is the most common cause of death in pulmonary arterial hypertension (PAH) and occurs when the RV can no longer adapt to the afterload (1). The definitive diagnosis of $\mathrm{PH}$ is made by cardiac catheterization.
However, the cost and risks associated with this invasive procedure have pushed clinicians to look for other means of evaluating the RV-pulmonary artery axis that is the basis of $\mathrm{PH}$ pathophysiology. The result is an impressive body of literature exploring the use of non-invasive imaging in the care of $\mathrm{PH}$ patients. Noninvasive imaging in $\mathrm{PH}$ is indeed critical in the diagnosis and follow up care, and part of the guidelines recommendation for pediatric and adult $\mathrm{PH}$ evaluation (3-7). These include established and novel modalities: two-dimensional (2D) and three-dimensional

\footnotetext{
^ ORCID: 0000-0001-5145-0341
} 
(3D) echocardiography for evaluation of morphology and functional assessment, cardiac magnetic resonance imaging (MRI) to quantify volumes and flows as well as to characterize the myocardium, and cardiac computed tomography (CT) for evaluation of the lung parenchyma and vasculature to rule out treatable causes of $\mathrm{PH}$. This review is an update of the latest advancement in the noninvasive imaging evaluation of pediatric and adult $\mathrm{PH}$.

\section{Echocardiography}

Transthoracic echocardiography (TTE) is the noninvasive modality of choice for the initial screening of suspected $\mathrm{PH}$. The optimal scaling parameters for RV metrics that would provide body size independence has not been well established across the spectrum of pediatric and adult patients. For this reason, the assessment of pediatric $\mathrm{PH}$ can have reference ranges different from those in adults, which may affect the accuracy of diagnosis in children with $\mathrm{PH}$ (8-10). Here, we combine established key parameters with newly developed TTE variables and modalities in adult and pediatric patients to assess potential RV dysfunction in PH. Conventional TTE imaging includes hemodynamic measurements and flow assessment by using Doppler echocardiography, evaluation of RV and left ventricular (LV) function and anatomy (11-14). Advanced TTE imaging includes multiparametric approaches, analysis of RV size and function using $2 \mathrm{D}$ and $3 \mathrm{D}$ echocardiography, $\mathrm{RV}$ to pulmonary arterial (PA) coupling ratio and myocardial mechanics (15-17). Standard evaluation of the LV (including end-systolic and diastolic LV eccentricity index, end-systolic RV/LV diameter ratio, classical indicators of diastolic LV dysfunction) is indispensable for complete and thorough evaluation by TTE since RV dysfunction and severe $\mathrm{PH}$ with systemic/supra-systemic RV pressure frequently affect diastolic and systolic LV function.

\section{Standard imaging}

\section{Estimation of pulmonary artery pressure (PAP)}

The estimation of systolic PAP (PASP) is based on the peak velocity of the tricuspid regurgitation jet (TRV) usually best obtained in a modified apical view. The simplified Bernoulli equation (PASP $=4 \times \mathrm{v} 2$ ), using continuous wave $(\mathrm{CW})$ Doppler to assess velocity within the TRV, describes the relationship of TR and right ventricular systolic pressure (RVSP) as a surrogate of PASP in the absence of an outflow tract obstruction or pulmonary artery (PA) stenosis (18).
Mean right atrial pressure (RAP) is added to this value to arrive at an estimated RVSP. In adults, TRV values $>3.4 \mathrm{~m} / \mathrm{s}$, usually correspond to a PASP $>50 \mathrm{mmHg}$ at rest, increasing the likelihood of PH. However, one must bear in mind that in cases with severe TR, PASP may be underestimated $(19,20)$.

The mean PAP (mPAP) can be calculated from the PASP $(\approx \mathrm{RVSP})$ as the $\mathrm{mPAP}=0.61 \times \mathrm{PASP}+2 \mathrm{mmHg}$, a formula that provides a great coefficient of determination in the pulmonary system $(21,22)$. This formula permits the use of Doppler measurements in screening for $\mathrm{PH}$, applying the accepted thresholds of mPAP of $25 \mathrm{mmHg}$ or more recently suggested $\mathrm{mPAP}>20 \mathrm{mmHg}$ and a pulmonary vascular resistance (PVR) index >3.0 Wood Units $\mathrm{m}^{2}$ (7).

If pulmonary regurgitation (PR) can be interrogated with CW-Doppler in the parasternal short axis (PSAX) view, mPAP and end-diastolic PAP can be estimated from the maximum (early diastolic) and minimum (end-diastolic) PR velocity, respectively, using the simplified Bernoulli equation and taking into account mean RAP. In diagnosis and follow-up of PH, mPAP and end-diastolic PAP should be routinely used, especially when TRV is unreliable (23).

\section{RV longitudinal systolic function}

Reflecting the longitudinal excursion of the tricuspid annulus towards the apex, tricuspid annular plane systolic excursion (TAPSE) is typically measured with M-mode in the apical 4-chamber view (24) (Figure 1A). Using the TAPSE as a surrogate measure of systolic RV function one has to bear in mind that the TAPSE takes into account neither segmental RV dysfunction/contractility nor radial systolic function, which usually contributes significantly to RV ejection in the setting of severe RV hypertrophy (13). Physiologically, TAPSE values increase from preterm infants to healthy adolescents with age and growth. Reference values for TAPSE are available for adults and pediatric patients (25-27). A reduced TAPSE marks abnormal longitudinal function of the RV with high specificity. For every $1 \mathrm{~mm}$ decrease in TAPSE, the unadjusted risk of death has been shown to increase by $17 \%$ in adult patients with PH (28). In children and adolescents with PH, TAPSE values diminish (z-score $<-2$ ) with increasing age compared with those in healthy age-matched controls which may indicate a decline of $\mathrm{RV}$ systolic function in $\mathrm{PH}$ due to permanent severe RV pressure overload $(25,29)$.

\section{Tissue Doppler velocities}

Tissue Doppler imaging (TDI) allows a quantitative 

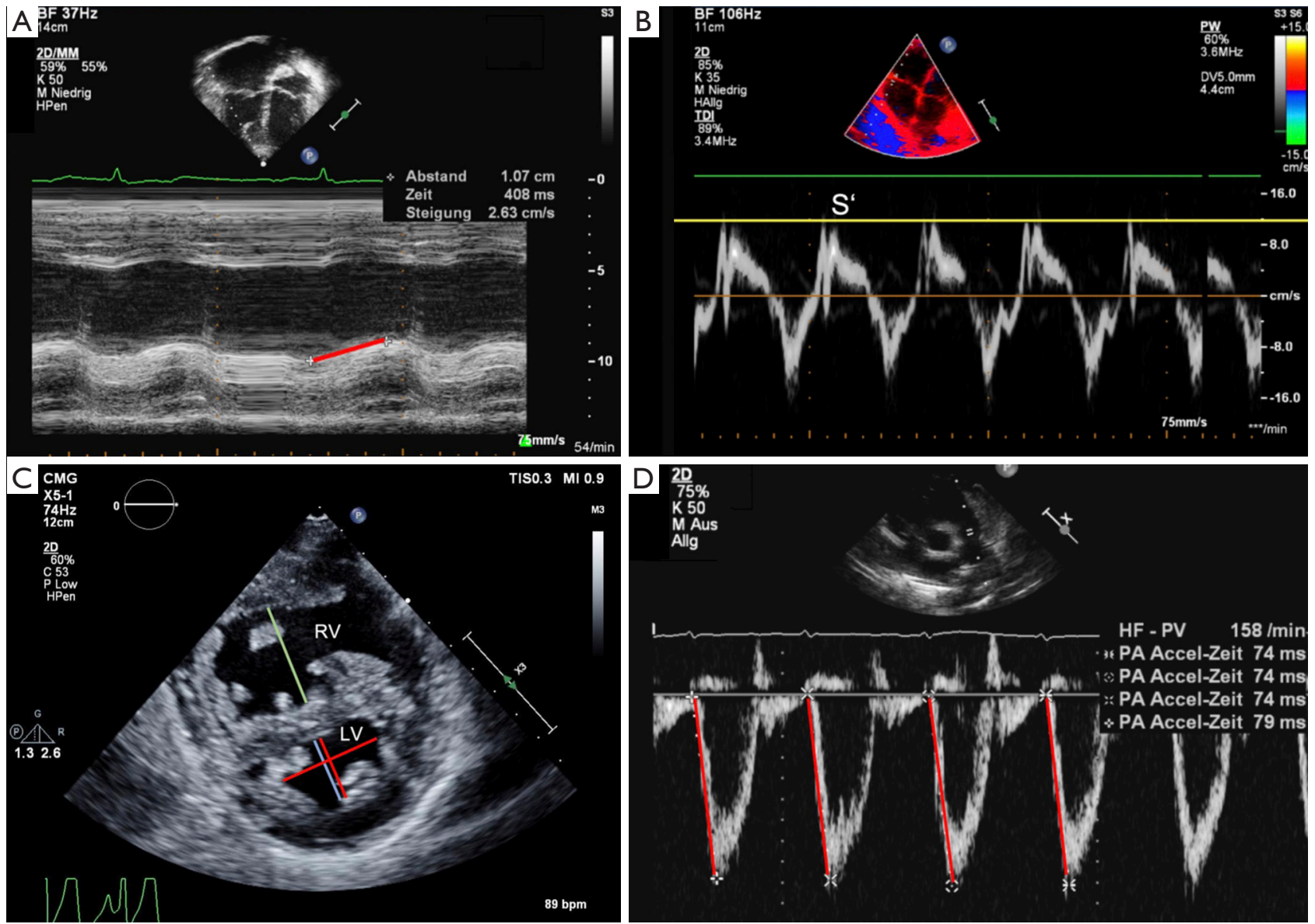

Figure 1 Transthoracic imaging. (A) Apical four-chamber view. Measurement of the tricuspid annular plane systolic excursion (TAPSE) in M-Mode in a 9-year-old patient with pulmonary arterial hypertension secondary to congenital heart disease (PAH-CHD). The red line shows a decreased TAPSE value and a flat course of the excursion. (B) Apical four-chamber view. Right ventricular (RV) tissue Doppler imaging (TDI) in a 10-year-old patient with PAH-CHD. The cursor is placed through the lateral tricuspid annulus. Note the dilated RV cavity, the reduced values of tricuspid annular peak systolic velocity (S'), depicted as the yellow line (measurement over 5 heart circles). (C) Parasternal short axis view of the right ventricle (RV) and left ventricle (LV) in an 8-year-old patient with idiopathic pulmonary arterial hypertension (IPAH). The LV appears D-shaped due to flattening of the interventricular septum caused by elevated RV pressure. The RV/LV ratio was derived at end-systole from RV and LV diameter. The severe RV dilation is highlighted by the green line whereas the LV compression is marked by the blue line. For determination of eccentricity index, the shorter red line represents the septal-lateral dimension and the longer red line the anterior-posterior dimension. (D) Parasternal short axis view. Pulmonary artery flow profile in the mean pulmonary artery in a 10-year-old-patient with IPAH. The red lines mark the rapid acceleration to peak flow velocity in early systole, followed by a fast deceleration in mid systole and a secondary increase in flow velocity in late systole. Compared to healthy subjects, this mean pulmonary artery acceleration time (PAAT) measured over 4 circles of $75 \mathrm{~ms}$ is reduced in this patient.

assessment of RV systolic and diastolic function by measurement of myocardial velocities (Figure $1 B$ ). As tissue velocities vary with age and heart rate, different reference values must be applied for adult and pediatric patients (30). Various studies revealed that in patients with $\mathrm{PH}$, systolic (S') and early diastolic (E') velocities at the tricuspid, septal, and LV wall are lower than in controls, highlighting the involvement of biventricular systolic and diastolic function (31-33). Cumulative event-free survival rate is suggested to be lower when tricuspid E' is $<8 \mathrm{~cm} / \mathrm{s}$ (33). TDI is independent of chamber geometry which permits its use in any chamber configuration. In pediatric $\mathrm{PH}$ patients 
associated with congenital heart disease, TDI measurements were able to demonstrate that the tricuspid annular peak $S^{\prime}$ is substantially impaired, with S' value continually decreasing with longer duration of pediatric $\mathrm{PH}$ (32). Of note the integral of the $\mathrm{S}$ wave yield a metric of TAPSE derived by the TDI.

\section{Presence of pericardial effusion (PE)}

In adult $\mathrm{PAH}$ patients, presence of $\mathrm{PE}$ even in small amounts applies as prognostic factor and was associated with poorer survival compared to patients without PE (34). Admittedly, in another study, the appearance of a new moderate or larger PE was associated with increased mortality in adult $\mathrm{PH}$ patients, whereas these findings could not have been determined in patients with only a small PE (35). In children, however, the prognostic meaning of $\mathrm{PE}$ in pediatric $\mathrm{PH}$ is unclear at this time due to lack of sufficient data. Furthermore, the definition of a significant PE in children remains controversial.

\section{RV fractional area change (FAC)}

The RV FAC is a measure for evaluation of $\mathrm{RV}$ contraction and is calculated as (diastolic RV area systolic RV area)/diastolic RV area. RVFAC encompasses both longitudinal and radial $\mathrm{RV}$ function from the base to the apex although it has the disadvantage of being less reproducible than TAPSE (28). In the context of RV enlargement when incomplete depiction of the RV cavity is common, RV FAC analysis will be associated with higher inter- and intraobserver variability (28). In children, a correlation between RV FAC and indexed RV stroke work and TAPSE has been reported (36) indicating the meaningfulness of an inclusion of RV FAC analysis also in pediatric $\mathrm{PH}$ patients. However, one must take into account that RV FAC is dependent on loading conditions as is TAPSE or longitudinal strain (36).

\section{Left ventricle (LV)}

The elevated RV pressure, as part of the pathophysiology in PH, leads to flattening of the interventricular septum. Consequently, the LV appears D-shaped and is more prominent in systole (37). In $\mathrm{PH}$, a reduction in LV systolic as well as in diastolic volumes can be observed, whereas the global systolic function is usually preserved when measured by ejection fraction (EF) $(6,8,37)$. $L V$ systolic function is often impaired when measured by LV longitudinal strain. Although not the focus of this review, evaluation of the $\mathrm{LV}$, including $\mathrm{LV}$ systolic function ( $\mathrm{LV} \mathrm{EF}, \mathrm{LV}$ fractional shortening), longitudinal systolic LV function (mitral annular plane systolic excursion), and inflow and outflow Doppler of all valves, should be an integral part of the echocardiographic assessment of $\mathrm{PH}$, to assess decremental $\mathrm{RV}-\mathrm{LV}$ interactions (38). Diminished LV torsion is associated with worsening RV function (39).

\section{Abnormal septal motion and eccentricity index}

The prescribed beforehand flattening of the interventricular septum commonly appears in end-systole which leads to an increased end-systolic LV eccentricity index (LVEI) (Figure 1C). LVEI is defined as the ratio of the minor axis of the $L V$ parallel to the septum divided by the minor axis perpendicular to the septum (6,37). An LVEI $>1$ has been shown to have prognostic value in adult idiopathic $\mathrm{PAH}$ (IPAH) patients (40-42). The abnormal septal movement in which the septum shifts into the LV creates a D-shaped LV in the parasternal short axis view (Figure $1 C$ ). This results in LV diastolic and systolic dysfunction $(31,43)$. Since RV dysfunction and advanced $\mathrm{PH}$ with systemic or suprasystemic RV pressure frequently affects LV function, TDI measurements of the left lateral wall and interventricular septum should also be performed $(6,37)$.

\section{LV diastolic function}

In pediatric $\mathrm{PH}$ patients, the $\mathrm{LV}$ function can be impaired furthermore through RV/LV interdependence $(31,44)$. Adult guidelines, published by the American Society of Echocardiography (ASE), suggest for evaluating LV diastolic dysfunction a cutoff value of E/e' ratio of $>14$ to potentially predict elevated left atrial pressures (45). Importantly, E/e' ratio appears not reliable in pediatric patients with $L V$ diastolic dysfunction. For instance, approximately $50 \%$ of children with a cardiomyopathy present with E/e' values within normal age adapted reference ranges (46). In the future, the diagnosis of $\mathrm{LV}$ diastolic dysfunction will likely be improved by the development of age specific thresholds for E/e' ratios.

\section{PA acceleration time}

The PA forward flow velocity profile, obtained in the right ventricular outflow tract (RVOT) with PW Doppler just proximal to the pulmonary valve, can be used to determine the PA acceleration time (PAAT) (Figure 1D). PAAT is the interval in milliseconds from the onset of ejection to peak flow velocity and is used for the estimation of RV pressure and PASP. Of note, the PAAT can be measured in $99 \%$ of patients, even when the TRV CW-Doppler 

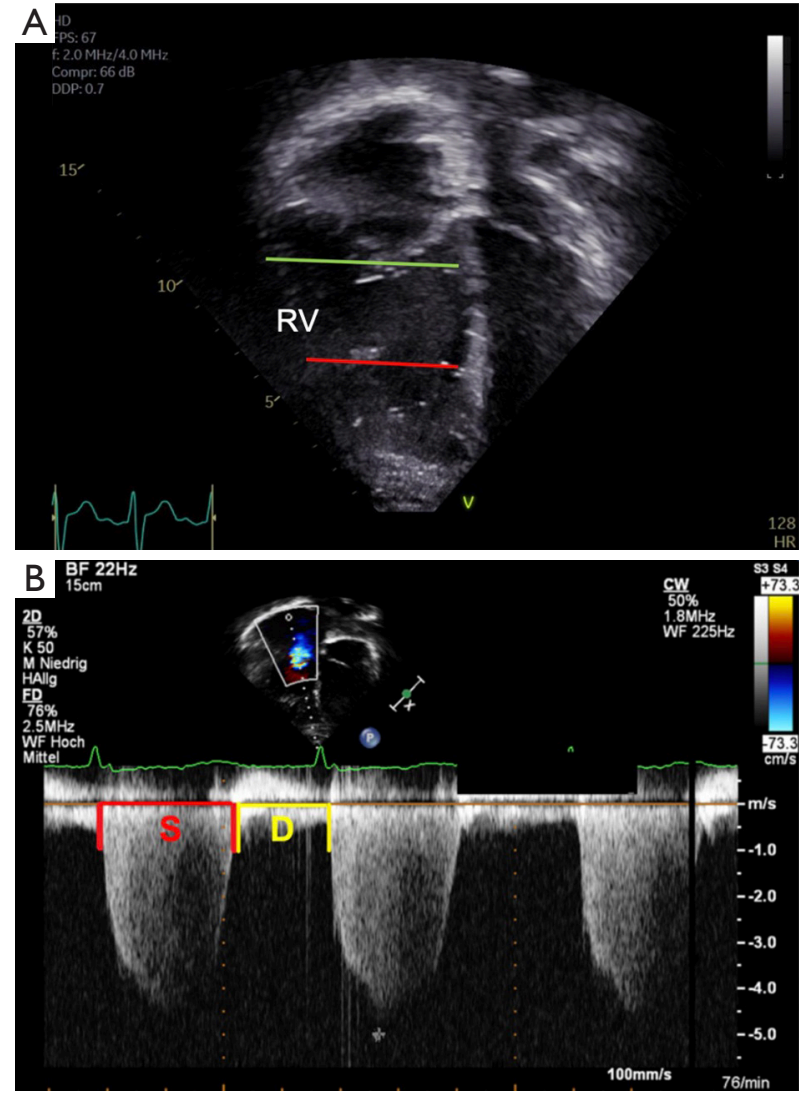

Figure 2 Transthoracic imaging. (A) Apical four-chamber view. Evaluation of the right ventricular end-systolic (RVES) base/ apex ratio in a 12 -year-old-patient with idiopathic pulmonary arterial hypertension (IPAH). The RVES internal diameter at the base (RVES b) is marked in green and the RVES apical internal diameter (RVES a) in highlighted in red. Note the dilated cavity of the RV. The dotted lines demonstrate the determination of the RV end-systolic area. (B) Apical four-chamber view. Dopplerderived systolic (S) to diastolic (D) duration ratio in a 14-year-old patient. For calculation of the S/D ratio, S and D duration using tricuspid regurgitation (TR) was measured view using continuous wave $(\mathrm{CW})$-Doppler. The red lines mark the $\mathrm{S}$ duration and the yellow lines the $\mathrm{D}$ duration of the cardiac circle. In this 12-yearold-patient with PAH-CHD the S/D ratio is increased.

envelope is not available or incomplete (47). A linear inverse relationship between PAAT and mPAP exists in adult patients with PAAT $<100 \mathrm{~ms}$ (48). A PAAT value of $<100 \mathrm{msec}$ is considered abnormal. Due to the fact that PAAT varies with heart rate, pediatric reference values and z-scores were established and could be used to identify $\mathrm{PH}$ children $(20,49)$. It has also been demonstrated that similar to PAAT, the RV ejection time (RVET) is reduced in adults and in children with $\mathrm{PH}$ (50). A ratio of PAAT/RVET is less dependent on age, body surface area (BSA) and heart rate. Therefore, PAAT/RVET is suggested to be meaningful in pediatric patients $(50,51)$. Furthermore, bronchopulmonary dysplasia and $\mathrm{PH}$ were described to have negative impact on PAAT measures, suggesting that PAAT and PAAT/RVET ratio can be used as complementary modalities to assess pulmonary hemodynamics in neonates (52).

\section{Advanced parameters}

\section{RV base/apex ratio}

The RV end-systolic base/apex (RVES b/a) ratio is a simple $2 \mathrm{D}$ index that takes into account the specific morphologic features of the RV (Figure 2A). It is considered of clinical value for assessment of $\mathrm{PH}$ in adults as well as in pediatric patients $(53,54)$. In the four-chamber view, the RV internal diameter at the base (RVES b) is measured just apical to the tricuspid annulus and the apical internal diameter of the RV (RVES a) is measured at the level of the distal end of the moderator band. Both diameters are determined in end-systole. In children and in adults $\mathrm{PH}$, the RVES b/a ratio was found to be lower than in healthy (age-matched) control subjects, mainly due to dilation of the RV base and apex $(53,54)$.

\section{Systolic-to-diastolic duration ratio}

Patients with significant $\mathrm{PH}$ have prolonged contraction of the RV, despite a shorter RV ejection time (55). This permits the use of systolic (S) to diastolic (D) duration ratio as an indicator of RV dysfunction (Figure 2B). In patients with $\mathrm{PH}$, the Doppler-derived S/D duration ratio is higher than in healthy controls, especially as heart rates increase (55). An S/D duration ratio $>1.4$ is inversely correlated with survival in pediatric $\mathrm{PH}$ (56). The $\mathrm{S} / \mathrm{D}$ duration ratio is independent of heart size, making this parameter useful in growing children. The S/D duration ratio, however, is dependent on a clearly defined onset and ending of TR Doppler tracings, so that Doppler derivation could be more reproducible (57).

\section{Right atrial (RA) function}

Assessment of the RA function can be highly relevant in $\mathrm{PH}$ patients. Adults with $\mathrm{PH}$ who lost RA function due to atrial fibrillation, have been shown to deteriorate clinically, with poor outcomes (58). An RA active emptying fraction $\geq 60 \%$ and a RV FAC $<25 \%$ are good predictors of clinical 


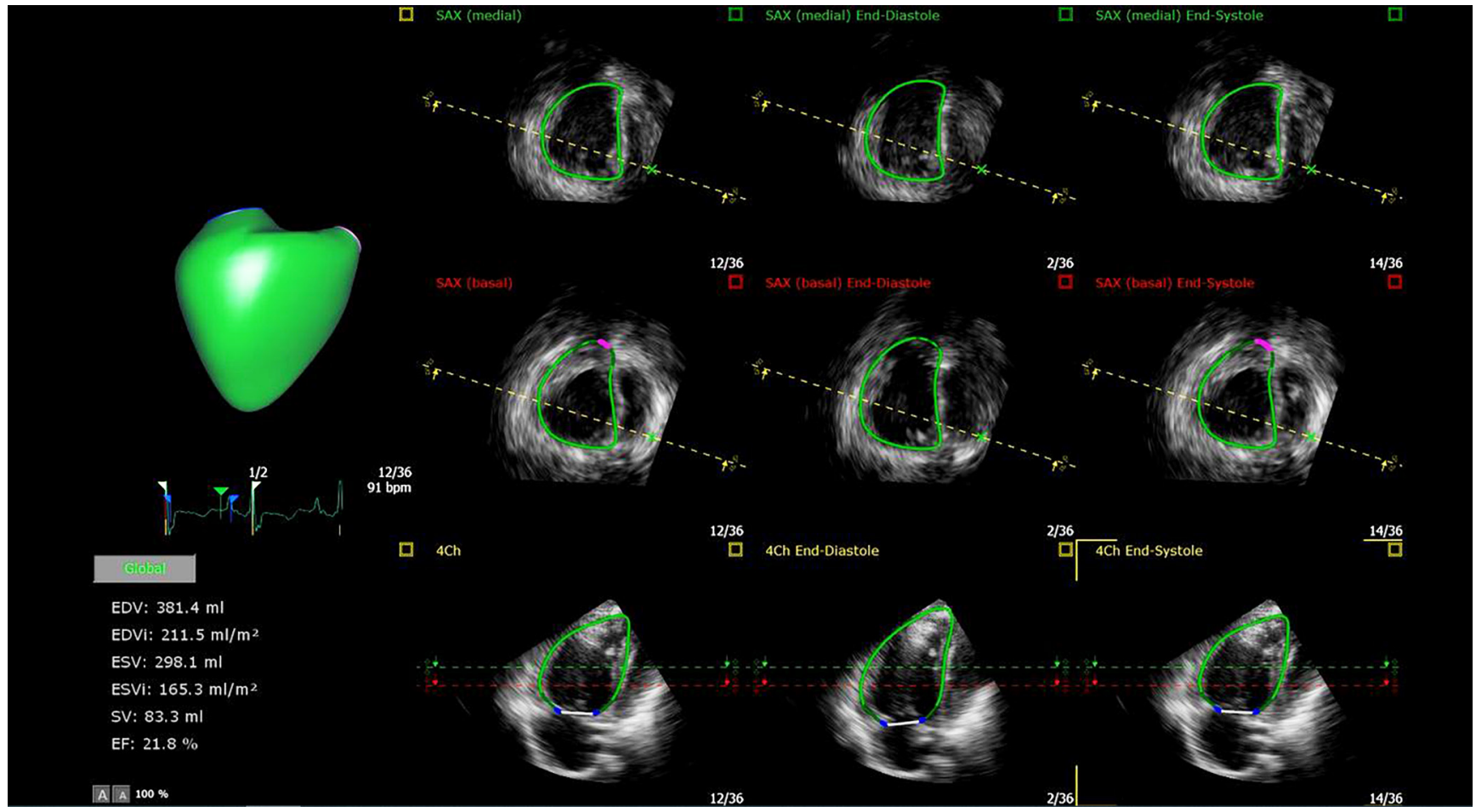

Figure 3 Three-dimensional echocardiography of right ventricular volumes and function in pulmonary hypertension patient.

worsening in pediatric $\mathrm{PH}$ (59). In pediatric $\mathrm{PH}$ patients, changes in RV diastolic function reflect worsening RA reservoir and conduit function (60). Furthermore, RA deformation indices have been shown to correlate with functional capacity, invasive hemodynamic parameters, and associated with poor outcomes in children with PH (60).

\section{RV enlargement}

In patients with $\mathrm{PH}, \mathrm{RV}$ dilation affecting the interventricular septum leads to septal shift toward the LV in systole. In severe $\mathrm{PH}$, progressive $\mathrm{RV}$ pressure overload results in RV failure and is related to underfilling and dysfunction of the compressed LV (61-63). RV/LV ratios measured in the PSAX were demonstrated as meaningfully higher in adult and pediatric patients with $\mathrm{PH}$ than in controls and correlated well with invasive hemodynamic measures (Figure 1C) $(62,64)$. Furthermore, an RV/LV ratio in end-systole $>1$ is associated with adverse clinical events $(64,65)$, highlighting the importance of ventricular interdependence in pediatric and adult $\mathrm{PH}$.

\section{Subcostal TAPSE}

Reference values and z-scores for subcostal TAPSE (S-TAPSE) were recently provided for adult and pediatric patients $(66,67)$. Like TAPSE values, S-TAPSE values at different ages are correlated with systolic RV function parameters. Especially in critically ill patients following cardiac surgery, evaluation of tricuspid annulus motion is often hampered in the four-chamber view due to wound dressings. In such settings, TAPSE can be determined from a subcostal view and may assist in identifying patients with reduced RV function $(66,67)$.

\section{D-echocardiography imaging}

Due to its complex geometric shape, capturing of the inflow and outflow tracts of the RV in the same time acquisition is nearly impossible using $2 \mathrm{D}$ echocardiography. $3 \mathrm{D}$-echocardiography (Figure 3 ) has proved to be a feasible complementary tool in quantifying RV function, validated with cardiac MRI in adult and pediatric patients $(16,17,68,69)$. Normal values of RV volumes and function have been reported in adults and children $(69,70)$. PH patients usually have larger RV volumes with lower EF than controls (17,71). Furthermore, PH groups vary in RV dysfunction severity: RV functional indices were worse in idiopathic PAH patients than in PAH-congenital heart disease patients (17). The 3D RV EF in pediatric 
$\mathrm{PH}$ has been correlated with hemodynamic parameters determined invasively, as well as biomarkers of severity (16). The investigation of $\mathrm{RV}$ arterial coupling ratio derived from 3D echocardiography by using stroke volume (SV) to end-systolic volume (ESV) in children with $\mathrm{PH}$ demonstrated that SV/ESV ratio is decreased in children with $\mathrm{PH}$ compared with controls. Furthermore, SV/ESV ratio correlated with RV strain and seemed to be a strong predictor of adverse clinical events in pediatric $\mathrm{PH}$ (72).

\section{$R V$ strain and strain measurements}

Strain is a measure of myocardial deformation whereas strain rate is defined as rate of deformation over time (13). Deformation imaging provides unique information on regional and global RV function. Reference values of adult and pediatric RV strain measurements are available (73-75). RV global longitudinal systolic strain and strain rate are substantially lower in adults with PH than in controls (76). Furthermore, RV strain provides incremental prognostic value over echocardiographic variables and could have been demonstrated as strong predictor of survival in $\mathrm{PH}(77)$. While on therapy, an individual improvement of $>-5 \%$ in absolute value in RV systolic strain at follow-up correlates with better pulmonary hemodynamics, improved clinical status, and less evidence of RV failure (78). Decreased longitudinal deformation, decreased or absent transverse shortening, and post-systolic shortening demonstrated RV dysfunction in children with IPAH (79). In a five year followup study, RV strain, as well as TAPSE measurements, was found to be worse in non-survivors compared to survivors at baseline and over 5 years (80). However, the differences observed in TAPSE between survivors and non-survivors were not as divergent as between the RV strain measurements (81). After initiation of prostacyclin analogues in pediatric $\mathrm{PH}$ patients, an early and sustained improvement in RV strain measures have been observed, indicating that RV strain may be sensitive marker of RV function in this population (82). Besides 2D strain variables, 3D strain parameters could have been demonstrated to show better association to RV failure hemodynamics than echocardiographic measurements in adults as well as in children $(17,80)$. The clinical application of $3 \mathrm{D}$ strain needs further research.

\section{Exercise stress echocardiography}

Exercise stress echocardiography is no longer part of the routine diagnosis of $\mathrm{PH}$ (5). A disease entity of exercise
$\mathrm{PH}$ is not recommended or used due to the lack of reliable data that define which levels of exercise-induced changes in pulmonary artery pressures or PVR are prognostic (83). There are no normal values established for pulmonary artery pressures during exercise. Therefore, it is difficult to determine if the rise in pulmonary artery pressure during normal exercise is related to physiologic increase or a true disorder of PVR. An increase in pulmonary artery pressure may occur during normal exercise without an increase in PVR $(84,85)$. One study has shown that RV dimension is increased in adult $\mathrm{PH}$ patients compared to controls during exercise stress echocardiography (86). Recent studies have suggested that mean pulmonary artery pressure rises by $\geq 1 \mathrm{mmHg}$ per liter of cardiac output in normal subjects, but pulmonary vascular disease patients have a rise of $\geq 3 \mathrm{mmHg}$ per liter of cardiac output (7). More research is needed for exercise stress echocardiography in $\mathrm{PH}$ as a diagnostic tool in adult and pediatric population. The use of pulmonary arterial pressure-cardiac output slope will likely be needed to better define $\mathrm{PH}$ with exercise. This needs at least three time points and assessment of both evaluation of RVSP and estimated cardiac output at rest, at peak, and in recovery.

In summary, echocardiography remains the first line imaging modality for the diagnosis and evaluation of the PH patient. 2D images measure right heart size, diastolic and systolic function, as well as give insight into the relative pressures of the right heart compared to the left. The relative ease of use and low cost make echocardiography an indispensable tool for clinical care as well as research. Often, a combination of parameters can comprehensively reflect the patient status. For example, FAC, LV eccentricity index, and RA and right ventricular sizes were all shown to improve in a study of patients initially diagnosed with severe $\mathrm{PH}$ receiving aggressive triple therapy (87). Color and spectral Doppler are used to access flow as a reflection of pressure and resistance. Advances in 3D echocardiography and strain will only make echocardiography more accurate and be able to pick up early changes before overt clinical deterioration. Limitation of echocardiography includes patients with poor acoustic windows in patients with lung disease.

\section{Magnetic resonance imaging}

The American College of Cardiology Foundation/American Heart Association (88) and the European Paediatric Pulmonary Vascular Disease Network (89) recommend both MRI and CT for prognostic information about the RV 


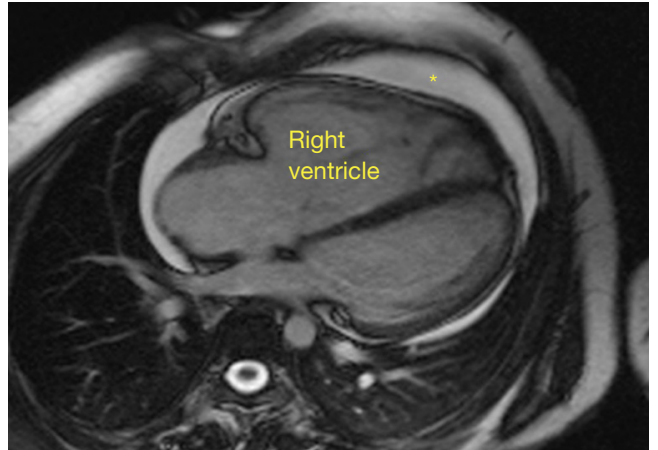

Figure 4 Cine image of the 4-chamber view of a patient with pulmonary hypertension demonstrates enlarged right atrium and dilated right ventricle, as well as the presence of pericardial effusion $\left(^{*}\right)$.

and lung parenchyma in the care of patients at baseline and follow-up. MRI has several critical advantages over other imaging modalities. Images by MRI offer high temporal and spatial resolution without exposure to ionizing radiation (Figure 4). Multiple studies have reinforced the high reproducibility of MRI-derived ventricular measures, making it the reference standard for volumetric and functional measures. Low cardiac variability in CMR imaging in PAH allows for a strong detection of clinically relevant changes with a small trial sample size, which is a critical point for the study of a relatively rare disease (90).

In addition, the ability to cross reference flow measures, including SV and cardiac output, with multiple approaches makes MRI unique. Especially in congenital heart disease in which patients may have chest wall scarring from repeated sternotomy or in adults with large body habitus, the anterior RV may be difficult to clearly delineate by echocardiography. MRI is not limited by either. The complex geometry of the RV makes straight-forward, easy mathematical approaches, as is done in elliptical-shaped LV, impossible. MRI makes no assumption about ventricular geometry. A number of conditions may preclude subjects from undergoing MRI. Pacemakers and ICDs should be fully evaluated for MRI compatibility. Metal artifacts can notoriously obscure imaging and should be considered. Claustrophobia, which is estimated to be $4 \%$ of subjects undergoing MRI, may not be previously recognized by the patient. The presence of arrhythmia may also make imaging difficult. MRI based approach also has longer scanning time and requires multiple breath-holds. MRI has relatively higher costs compare to echo. Finally, investment in proper training of MRI technologists and post-processing analysts is critical.

Currently, standard of care is using cardiac catheterization to establish $\mathrm{PH}$ diagnosis and hemodynamics, including PVR and mPAP. It is important to point out that cardiac catheterization data focuses on only the vasculature, while MRI has the ability to establish data on both the ventricle and the vasculature, and thus, a more comprehensive evaluation of the pathophysiology of $\mathrm{PH}$. Over the past decade, growing literature supports the use of RV parameters in combination with vascular parameters to be more predictive of outcomes in $\mathrm{PH}$ than PVR. The first report to show this included 64 adult $\mathrm{PH}$ patients and found that progressive RV dilation and decrease of $\mathrm{LV}$ end-diastolic volume at 1 year follow-up were the strongest predictors of mortality (91). Soon after this, multiple reports showed similar findings, with measures of volume, $\mathrm{EF}$, and $\mathrm{SV}$ shown to be powerful predictors of survival in PH (92-95). RVEF has also gained attention. A critical paper by van de Veerdonk et al. followed 110 patients with $\mathrm{PH}$, acquiring baseline and 12 months CMR and cardiac catheterization. The authors found that patients with low RVEF had significantly decreased survival compared to higher RVEF independent of the PVR. Twenty-five percent of $\mathrm{PH}$ patients with reduced PVR over a median 59-month follow-up still had deterioration of RV function. In fact, comparison of survivors and non-survivors showed no change in PVR, but a clear deterioration of RVEF in the non-survivors compared to survivors (95). Similarly, in children, in the largest published cohort, Moledina showed prognostic potential of $\mathrm{RV}$ and $\mathrm{LV}$ volumetric measures for predicting death or transplant (94). Thus, this shifted the conventional paradigm from relying on a single PVR to understanding the interplay of the RV-PA axis.

\section{Ventricular vascular coupling (VVC)}

In a healthy cardiovascular state, the ventricle adapts to changes in the arterial afterload by altering contractility in order to maintain adequate SV at the most efficient myocardial work. Response of the RV initially to rising afterload is increasing hypertrophy. At the point when this is no longer adequate, the RV becomes increasingly dilated, thus increasing diastolic volume to maintain SV. Heart rate will also increase. Both of these changes shift the system to higher myocardial consumption. Uncoupling occurs when myocardial adaptations are no longer sufficient to maintain cardiac output (1). The interaction between the RV and 
the PA can be conceptualized by the VVC ratio, with the numerator being the ventricular contractility $\left(\mathrm{E}_{\mathrm{es}}\right)$ and the denominator being the arterial elastance $\left(\mathrm{E}_{\mathrm{a}}\right)$. Arterial elastance $\left(E_{a}\right)$ represents vascular afterload. VVCR (as $\left.E_{e s} / E_{a}\right)$ is theoretically optimal at $1.5-2$, but in progressive loadincreasing diseases associated with failing ventricular function such as PAH, VVCR eventually decreases. VVCR is thought to decrease little in early stages of load-increasing disease such as $\mathrm{PH}$, as $\mathrm{SV}$ is maintained by augmented $\mathrm{RV}$ contractility. In late stages of disease, the RV fails to adapt and a further decrease in VVCR is expected. Conventionally, VVCR is measured by cardiac catheterization, with progressively decreasing preload achieved by obstructing flow through the inferior vena cava-a time-consuming and invasive methodology, not to mention impossible in very young children secondary to the size of the catheter used. Sanz showed that VVCR can be estimated using only MRI data $\left(\operatorname{VVCR}_{\mathrm{CMR}}\right)$ and is calculated as $\mathrm{SV} / \mathrm{ESV}$ (96), and correlates to VVCR derived by the catheterization-based single beat $\left(\mathrm{VVCR}_{\mathrm{RHC}}\right)$ method $(97,98)$. It is important to understand that this estimation assumes zero intercept of the ventricular elastance curve which limits its accuracy. Despite this, $\mathrm{VVCR}_{\mathrm{CMR}}$ remains a valuable tool, especially when followed longitudinally. In adults and children, both $\mathrm{VVCR}_{\mathrm{CMR}}$ and $\mathrm{VVCR}_{\mathrm{RHC}}$ correlated well with conventional functional and hemodynamic parameters of disease severity $(96,98)$, as well as clinical deterioration (99) and transplant-free survival (100). Impaired right ventricular-vascular coupling in $\mathrm{PH}$ is likely to be a gradual and progressive feature and serial imaging could guide the clinician in this process.

\section{Myocardial strain}

MRI can measure myocardial strain by two technique: tissue tagging and feature tracking. The first uses a pre-pulse to nullify signals within defined parallel lines or grids. These "tags" are then followed throughout the cardiac cycle, with each tag representing small regions of the myocardium. Feature tracking is a more novel approach, and uses steadystate free precession sequences images in multiple planes to determine deformation in the longitudinal, circumferential, and radial directions by following the movement of the myocardial border over the cardiac cycle (101). This method has been validated against tagged MRI (101). In a study looking at feature tracking of the RV, RV strain correlated with $R V \mathrm{E}_{\mathrm{es}} / \mathrm{E}_{\mathrm{a}}$ and afterload $\left(\mathrm{E}_{\mathrm{a}}\right)$, but not with contractility $\left(\mathrm{E}_{\mathrm{es}}\right)$. Multivariate logistic binary regression analysis identified long-axis RV radial strain as being able to identify RV-arterial uncoupling (102). In exercise states, $\mathrm{PH}$ patients showed less reserve than controls, as reflected by displaying significant decrease in longitudinal RV strain despite normal EF (103). Strain has been used in several studies of therapeutic response $(104,105)$.

Ventricular mechanics such as torsion and torsion rate can also be determined from strain analysis. Dysfunction of the RV compromises both diastolic and systolic function of the LV through ventricular-ventricular interaction. In $\mathrm{PH}$ patients, it is not surprising that $\mathrm{LV}$ torsion and torsion rate are decreased as RV EF decreases (39). In PH patients compared to normal subjects, smaller changes in RVEF lead to larger compromise of $\mathrm{LV}$ torsion rate (39). Hence, accurate diagnosis of the function and anatomy of both ventricles is essential in the pathophysiology of $\mathrm{PH}$.

\section{Tissue characterization}

One of the biggest advantages of MRI is the ability to provide details about the myocardium, by bringing out differences in signals for varying tissue composition to identify myocardial pathologies. T1 relaxation time is the time for a nuclear spin to return to $63 \%$ of its magnetization in the longitudinal plane. T1-weighted imaging is used to identify scar or fatty infiltration of the myocardium. $\mathrm{T} 2$ reflects the presence of water, and tissue edema (106). Using T1 and T2 tissue characterization with CMR permits investigation beyond the cardiomyocyte to understanding histopathologic changes - a process not available with other imaging modalities. The failing $\mathrm{RV}$ in $\mathrm{PH}$ is associated with myocardial edema, as shown in rodents by histologic confirmation, as well as T2-weighted MRI imaging.

In recent years, the development of new MR sequences enabled the quantitative measurement of $\mathrm{T} 1$ and $\mathrm{T} 2$ magnetization properties, known as T1 and T2 mapping, which have allowed for further characterization of changes in the underlying myocardial substrate. The diffuse nature of the fibrosis, for example, makes imaging by T1-weighted approaches impractical since $\mathrm{T} 1$-weighted imaging identified fibrosis as a hyperintense signal compared to myocardium. T1 mapping however can identify diffuse fibrosis, in which collagen has accumulated within the myocardium leading to diastolic dysfunction. In $\mathrm{PH}$ patients, native T1 (performed pre-contrast) and T2 mapping are increased in the RV insertion points, with abnormal T2 values also seen in the RV free wall (107). Extracellular volume (ECV) fraction quantification can be 


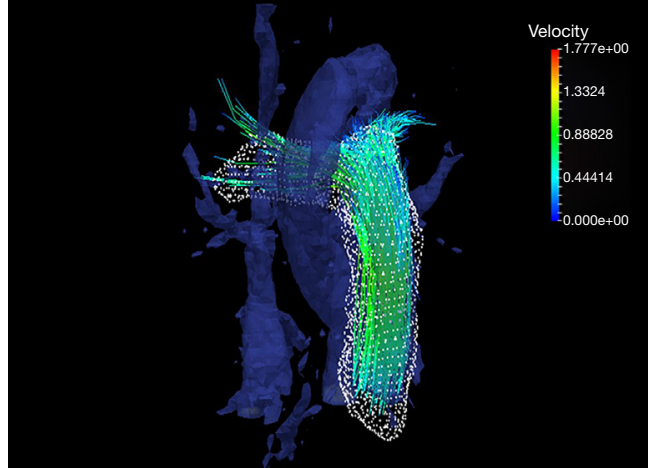

Figure 5 Streamlines through the main and branch pulmonary arteries from 4-dimensional MRI dataset. Generated pulmonary artery mask shows boundaries of arterial wall.

determined by measuring T1 mapping before and after contrast. In PH porcine models, ECV was higher in the RV insertion point and correlated with PVR, MPAP, RVEF, and PA area (108). Studies in humans concur $(109,110)$, with elevated native T1 and ECV seen even before the presence of late gadolinium enhancement (LGE) (110).

\section{$L G E$}

LGE is a technique by which images are acquired 5-10 minutes following gadolinium contrast administration. The presence of gadolinium within the myocardium after this time represents a breakdown of cell membrane, allowing intercalation of contrast into extracellular spaces. This is seen with fibrosis and ischemic changes. Hyperenhancement is seen in $69-83 \%$ of $\mathrm{PH}$ patients $(111,112)$, and often seen in the RV insertion points, correlating to regions of highest stress. However, its prognostic value remains uncertain. The literature is conflicting as to the use of LGE in PH. The presence of LGE has been linked to more severe disease state (113), longer disease duration (114), increased RV dilation, and to worsening RV function (112). Less clear, is the relationship between LGE and RV EF, with reports indicating polar opposite findings (113-115). Two large studies looked at 162 patients (111) and 124 patients (116), neither of which found correlation with mortality or morbidly including hospitalized RV failure, initiation of parenteral prostacyclin, sustained ventricular arrhythmia, or referral for lung transplant. Differences between studies may reflect a difference in etiologic make-up of study populations and distinction between LGE in the insertion points and extended involvement into the interventricular septum.

\section{Vascular imaging}

CMR is now emerging as a technique for evaluating vascular function as well, including flow patterns, flow velocity, wall shear stress (WSS) (117), and recently, vorticity and helicity by 4-dimensional (4D) velocityencoded MRI (118) (Figure 5). It can accurately and noninvasively quantify aortic velocity fields, allowing for the calculation of heterogeneously evolving WSS, as well as provide information on flow, turbulent kinetic energy, and vorticity (119). MRI also may demonstrate developmental vascular changes in $\mathrm{PAH}$, which is particularly important in pediatric $\mathrm{PH}$, in which disease progression is occurring simultaneously with development (120). Cross section analysis of the proximal pulmonary arteries can give accurate measures of arterial stiffness. These measures include relative area change, defined as $\left(\mathrm{Area}_{\text {systole }}-\right.$ Area $\left._{\text {diastole }}\right) /$ Area $_{\text {diastole }}$, compliance, and distensibility. Measures of arterial stiffness are predictive of mortality in $\mathrm{PH}$ (121). In fact, RAC was found to be the strongest predictor of mortality independent of pulse pressure.

Phase contrast (PC) imaging uses phase shift from flowing blood to quantitate flow and its derivatives, so that volume, velocity, and direction of flow can be determined. Pulse wave velocity (PWV), another measure of stiffness, can be measured from PC imaging from the flow-area method $(\mathrm{dQ} / \mathrm{dA})$ in which flow and area change waveforms (122). $\mathrm{PWV}$ in $\mathrm{PH}$ is a potential predictor of hospitalizations, increasing symptoms, and escalation of therapy (123).

WSS, an important hemodynamic component affecting mechanotransduction (124), is the shear that is seen by the endothelium caused by moving blood and can be measured from PC MRI (123). Acute and chronic changes in WSS associated with high flow pulsatility and disturbed flow has been shown to alter downstream signalling cascade, and can lead to vasodilation or vasoconstriction, endothelium proliferation, and alter coagulation cascade $(125,126)$. Indeed, WSS in the main and branch pulmonary arteries is decreased in $\mathrm{PH}$, in which flow derangements including vortex formation have been shown by time resolved 3D (127) and 4D flow MRI (128). This correlates with increasing arterial stiffness and decreased RV function (129). In addition, oscillatory shear index (OSI), the deviation of shear stress from its principle direction, can be derived from the WSS waveform. High OSI value is seen with compromised endothelial function and atherosclerotic changes (130), and is abnormal in the pulmonary arteries of 
adult and pediatric $\mathrm{PH}$ patients (129).

Like many cardiovascular diseases, flow alterations play a critical role in the progression of $\mathrm{PH}$. Abnormal cardiac vorticity, for example, is involved in the early development of cardiac dysfunction (131). Thus far, flow has been understudied due to limitations of imaging modality, until the development of 4-D flow MRI. 4D MRI allows the acquisition of flow data in all three dimensions of space over time (132). This unique feature allows the visualization and quantification of complex flows that is critical to normal and diseased physiology with high spatial resolution. For example, the normal vortex formation around the mitral anterior leaflet during early filling is lost in PH. It is this vortex in the healthy state that places the volume of blood directly in the LV outflow tract to be ejected during the next systolic phase. Therefore, this loss may compromise the efficiency of the system. The loss of this vortex is hypothesized to be due to the septal shift and alteration in septal geometry in PH (133). In addition, abnormal vorticity (local spins of fluid) in the inflow of both the RV and LV is seen in PH (134,135). In COPD patients with normal LV volumetric measures and normal diastolic Doppler indices, vorticity is already reduced; thus, may be a sensitive marker for early diastolic dysfunction (134).

Pressure estimation by Doppler using the Bernoulli's equation gives proof of concept to the ability of flow to estimate pressure. 4D MRI has not only shown decreased vorticity in the proximal pulmonary arteries, but multiregression models using 4D data in $\mathrm{PH}$ by Kheyfets et al. showed that vorticity may estimate PVR using a function of vorticity in the MPA, RPA, cardiac output, and the relative area change in the MPA. The equation predicts $94 \%$ of the variability in PVR (136). A meta-analysis covering 15 studies that analyzed the estimation of PVR by MRI showed no statistically significant differences in PVR estimated by MRI and that derived by catheterization (137). Of note, this meta-analysis included multiple MRI approaches with no standard protocol. Much work is still needed, but MRI is a promising tool for providing accurate data about the myocardium and vasculature in $\mathrm{PH}$ patients that can be followed serially.

\section{Exercise $M R I$}

The ability to perform exercise stress to MRI imaging has been a powerful advancement for its ability to clearly define myocardial borders even with a tachypneic and tachycardic patient. Exercise testing can unmask signs and symptoms, as well as limitations that are not appreciated at rest. Recently, exercise cardiovascular MRI demonstrated that low risk versus high risk $\mathrm{PAH}$ patients can be differentiated; that is, MRI during exercise stratifies patients into different degrees of right ventricular inotropic reserve. Patients were evaluated based on World Health Organization Functional Classification I and II. Those in class I were able to increase SV with exercise, while those in class II did not have this ability (138). Reduced SV during exercise is a determinant of increased risk of decompensation. Understanding exercise limitation could help guide therapy towards incorporating restoration of ventricular functional reserve by intensified PAH specific treatment.

\section{Ventricular-ventricular interaction}

Ventricular-ventricular interaction - the phenomenon in which the performance of each ventricle affects the otherhas been well described (139). In a study of isolate canine hearts, the left ventricle contributed to $68 \%$ of normal RV systolic pressure and $80 \%$ of pulmonary arterial flow (140). While the LV strain, particularly along the septum, is negatively affected in PH as shown by feature tracking (141), this in turn further reduces RV performance (Figure 6) (39).

MRI allows accurate assessment of SV and peak emptying rate (PER) during systole and early diastolic peak filling rate (PFR) for both the RV and LV. In a volume-time curve, PER is the maximal negative velocity during systole, and PFR is the maximal positive velocity in early diastole. Both were shown to correlate with SV. Thus, both can be additional surrogates for biventricular diastolic dysfunctions (142).

Another mechanism by which LV function is reduced in $\mathrm{PH}$ is the alteration of flow and blood volume in and out of the LV. As previously mentioned, in $\mathrm{PH}$, the vortex along the anterior mitral leaflet is lost, which is thought to efficiently deliver a bolus of blood to the LVOT to be ejected with the next contraction (131).

\section{Vascular-vascular interaction}

While not often considered, the aorta is also adversely affected in $\mathrm{PH}$. We showed that the presence of a dilated main pulmonary artery mechanically constrains the expansion of the adjacent ascending aorta, leading to decreased RAC. The lower RAC was not seen in the descending aorta (143). This apparent regional aortic stiffness is seen by the $\mathrm{LV}$ as increased afterload. Our data suggests that the degree of decreased RAC correlates with 


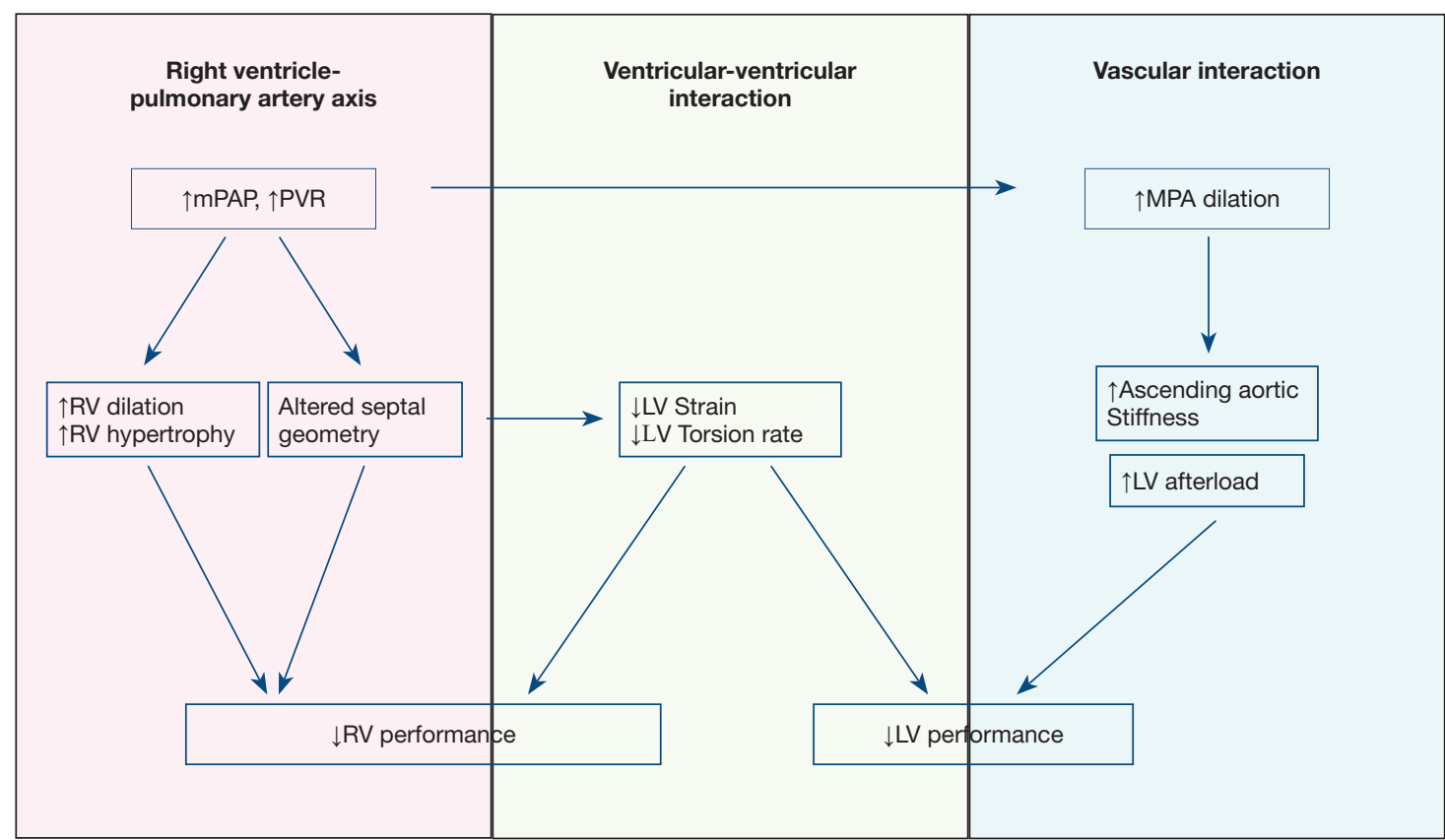

Figure 6 Summary diagram of the complex interplay of cardiovascular components involved in pulmonary hypertension. The right ventricle-pulmonary axis is often the focus, reflecting the initial response and subsequent maladaptation of the right ventricle to the rising pulmonary vascular resistance, leading to right ventricular failure. However, changes in the septal geometry with the rise in right ventricular systolic pressure, leads to decreased septal strain and left ventricular torsion, as well as a loss of efficient movement of blood flow through the left ventricle. Decrease in left ventricular function, in turn, contributes to the deterioration of the right ventricle. Finally, as the main pulmonary artery dilates with disease progression, this constrains the expansion of the adjacent ascending aorta. This regional increase in aortic stiffness is seen by the left ventricle as increased afterload, further affecting left ventricular performance. LV, left ventricle; MPA, main pulmonary artery; mPAP, mean pulmonary artery pressure; PVR, pulmonary vascular resistance; RV, right ventricle.

lower LVEF and lower VVCR. This is yet another possible mechanism by which disease of the RV-PA axis affects both LV performance (Figure 6).

In summary, MRI allows high spatial resolution of the intracardiac structure and vascular involved in $\mathrm{PH}$ pathophysiology. MRI is not constrained by body habitus, which is a significant advantage in older patients, those with poor acoustic windows, and those with surgical scars. The unusual geometry of the RV does not preclude accurate measurements of RV volume and EF. Advances in MRI have allowed detailed assessment of flow through the heart and the vasculature and reflect vascular hemodynamics and vascular remodeling. Despite important limitations, MRI is a promising tool to comprehensively describe the entire $\mathrm{RV}$-PA axis, as well as the involvement of the left heart.

\section{Computed tomography}

CT is important for identifying vascular, cardiac, parenchymal and mediastinal abnormalities (89). Details about pulmonary nodules, extracardiac shunts, bronchial and vascular anomalies are seen with a very short acquisition time by CT. Advances with multidetector (MDCT) have improved both spatial and temporal resolutions, allowing the development of high resolution CT applications (144). MDCT (also known as multislice CT) is an advancement from the conventional single slice CT, and has multiple rows of detectors, enabling more than one slice of data to be collected at any given time. High resolution CT without contrast is used for evaluation of lung parenchymal issues, especially in cases of $\mathrm{PH}$ suspicious for falling under Nice Classification Group 3. Parenchymal findings associated with different etiologies of $\mathrm{PH}$ include ground glass nodules seen in idiopathic PAH or pulmonary veno-occlusive disease interlobular thickening seen in left heart disease, pulmonary fibrosis, or sarcoidosis, ground glass opacities seen in pulmonary edema, interstitial lung disease, connective tissue disease. Enlarged bronchial arteries can be seen in CTEPH 
and Eisenmenger disease. Of note, bronchial artery dilation is often not presented in idiopathic PAH (145). Automated $3 \mathrm{D}$ volume segmentation is available with CTA can significantly decrease time for post-processing to as quick as 3 minutes (146).

Filling defects as seen in CTEPH is best seen with CT, along with associated findings of mosaic attenuation and enlarged bronchial arteries (145). CT can also identify PE and thickening seen in moderate to severe $\mathrm{PH}$ (147).

Limitations of MDCT include exposure to ionizing radiation and potentially nephrotoxic contrast, as well as being restricted to a low and stable heart rate for adequate acquisition of the myocardium. Imaging of the vasculature without need for myocardial imaging can be done with nonEKG gating.

Superior to other non-invasive imaging, CT scan image more proximal pulmonary arteries and veins. Therefore, details such as peripheral pruning can be seen. Mosaic attenuation is seen in $\mathrm{PH}$ and is a process by which there is dilation of vessels in areas of high attenuation and rarefaction of vessels in low areas of attenuation. This is thought to be due to regional differences in perfusion (148). Similarly, changes in segmental and subsegmental bronchi can be easily seen. A number of sentinel papers have shown reasonable sensitivity and specificity in using CTA for $\mathrm{PH}$ diagnosis by visualization and measurement of the pulmonary arteries $(149,150)$. A mean PA diameter $>29 \mathrm{~mm}$ has $87 \%$ sensitivity and $89 \%$ specificity for the diagnosis of $\mathrm{PH}$. This specificity can reach $100 \%$ if there is also segmental artery:bronchus ratio $>1: 1$ in 3 of 4 lobes (149). Another approach focusing on the ratio of main pulmonary artery diameter to the ascending aorta of $>1$ has a $96 \%$ positive predictive value $(150,151)$.

In patients in whom MRI is not ideal, CT can serve as an alternative to volumetric measures. In a meta-analysis comparing CT to MRI for RV measurements, 19 studies were reviewed which had CT performed less than one month from MRI. There was no statistical difference between the two modalities in RV volumetric measurements and EF, albeit CT overestimated EDV and ESV, and underestimated RVEF and SV (152). In a small study of 30 patients with PAH, 6MWT had higher correlation to MRI-derived RV parameters compared to CT (153). Similarly, a study of 812 patients with PAH from connective tissue disorders underwent CT, MRI, and RHC within 48 hours. CT derives RV and $L V$ ratio and RV thickness did not perform diagnostically as well as MRI -derived data. Furthermore, MRI parameters were more prognostic with 1-year survival compared to CT (154).

A brief mention about SPECT imaging in $\mathrm{PH}$ is warranted. Small studies have looked at the use of stress ${ }^{99}{ }^{9} \mathrm{Tc}$ SPECT perfusion studies in assessing the RV in $\mathrm{PH}$ (155). The increased uptake of ${ }^{99 \mathrm{~m}} \mathrm{Tc}$-labeled tracer is consistent with RV dilation as well as RV hypertrophy (156). An RV/LV ratio of 0.35 on non-attenuation corrected SPECT images had a sensitivity of $72 \%$ and specificity of $70 \%$ for identifying a pulmonary systolic pressure of $>40 \mathrm{mmHg}$. This is drastically compromised when attenuation correction is used as there is a higher false positive rate for RV hypertrophy.

In summary, CT is critical for evaluation of the lung parenchyma and pulmonary vasculature as part of the evaluation for PH. In patients in whom MRI is contraindicated, CT can give accurate measurements of RV volume and EF. Chest CT can be completed within a matter of minutes, although the downsides include exposure to ionizing radiation and potential renal toxicity associated with iodinated dye used in CT.

\section{Conclusions}

Noninvasive imaging is important in the diagnosis and follow up of $\mathrm{PH}$. Valuable information can be gained from these noninvasive measures to make clinical decisions and management of $\mathrm{PH}$ as invasive measurements pose risks for these patients. There is growing evidence that the deterioration of the RV function may be more predictive of PVR of outcomes. If this is indeed true, standard approach using cardiac catheterization is wholly inadequate to serially evaluate $\mathrm{PH}$ subjects. Rather, we must look towards noninvasive imaging as a safe and accurate means of providing comprehensive data of the ventricles, pulmonary and systemic circulation involved in $\mathrm{PH}$ progression. Further research will help define the most valuable parameters in determination of long-term prognosis.

\section{Acknowledgments}

Funding: None.

\section{Footnote}

Provenance and Peer Review: This article was commissioned by the Guest Editors (Martin Koestenberger, HarmJan Bogaard and Georg Hansmann) for the series "Right Ventricular Dysfunction" published in Cardiovascular 
Diagnosis and Therapy. The article was sent for external peer review organized by the Editor-in-Chief and the editorial office.

Conflicts of Interest: All authors have completed the ICMJE uniform disclosure forms (available at http://dx.doi. org/10.21037/cdt-20-272). The series "Right Ventricular Dysfunction" was commissioned by the editorial office without any funding or sponsorship. MK served as the unpaid Guest Editor of the series. UT reports grants from NIH NHLBI, from null, outside the submitted work. JC reports grants and other from Actelion, grants from Astra Zeneca, grants from United Therapeutics, outside the submitted work. DI reports grants and non-financial support from Actelion, grants from Bayer, grants from Glaxo Smith Kline, grants from Liquidia, grants and nonfinancial support from United Therapeutics, grants from Lilly, outside the submitted work. The other authors have no other conflicts of interest to declare.

Ethical Statement: The authors are accountable for all aspects of the work in ensuring that questions related to the accuracy or integrity of any part of the work are appropriately investigated and resolved.

Open Access Statement: This is an Open Access article distributed in accordance with the Creative Commons Attribution-NonCommercial-NoDerivs 4.0 International License (CC BY-NC-ND 4.0), which permits the noncommercial replication and distribution of the article with the strict proviso that no changes or edits are made and the original work is properly cited (including links to both the formal publication through the relevant DOI and the license). See: https://creativecommons.org/licenses/by-nc-nd/4.0/.

\section{References}

1. Vonk Noordegraaf A, Westerhof BE, Westerhof N. The Relationship Between the Right Ventricle and its Load in Pulmonary Hypertension. J Am Coll Cardiol 2017;69:236-43.

2. Vonk-Noordegraaf A, Haddad F, Chin KM, et al. Right heart adaptation to pulmonary arterial hypertension: physiology and pathobiology. J Am Coll Cardiol 2013;62:D22-33.

3. Abman SH, Hansmann G, Archer SL, et al. Pediatric Pulmonary Hypertension: Guidelines From the American Heart Association and American Thoracic Society.
Circulation 2015;132:2037-99.

4. Rosenzweig EB, Abman SH, Adatia I, et al. Paediatric pulmonary arterial hypertension: updates on definition, classification, diagnostics and management. Eur Respir J 2019. doi: 10.1183/13993003.01916-2018.

5. Galiè N, Humbert M, Vachiery JL, et al. 2015 ESC/ERS Guidelines for the diagnosis and treatment of pulmonary hypertension: The Joint Task Force for the Diagnosis and Treatment of Pulmonary Hypertension of the European Society of Cardiology (ESC) and the European Respiratory Society (ERS): Endorsed by: Association for European Paediatric and Congenital Cardiology (AEPC), International Society for Heart and Lung Transplantation (ISHLT). Eur Heart J 2016;37:67-119.

6. Hansmann G, Koestenberger M, Alastalo TP, et al. 2019 updated consensus statement on the diagnosis and treatment of pediatric pulmonary hypertension: The European Pediatric Pulmonary Vascular Disease Network (EPPVDN), endorsed by AEPC, ESPR and ISHLT. J Heart Lung Transplant 2019;38:879-901.

7. Simonneau G, Montani D, Celermajer DS, et al. Haemodynamic definitions and updated clinical classification of pulmonary hypertension. Eur Respir J 2019. doi: 10.1183/13993003.01913-2018.

8. Bossone E, D'Andrea A, D'Alto M, et al. Echocardiography in pulmonary arterial hypertension: from diagnosis to prognosis. J Am Soc Echocardiogr 2013;26:1-14.

9. Cordina RL, Playford D, Lang I, et al. State-of-the-Art Review: Echocardiography in Pulmonary Hypertension. Heart Lung Circ 2019;28:1351-64.

10. Rudski LG, Lai WW, Afilalo J, et al. Guidelines for the echocardiographic assessment of the right heart in adults: a report from the American Society of Echocardiography endorsed by the European Association of Echocardiography, a registered branch of the European Society of Cardiology, and the Canadian Society of Echocardiography. J Am Soc Echocardiogr 2010;23:685713; quiz 86-8.

11. D'Alto M, Bossone E, Opotowsky AR, et al. Strengths and weaknesses of echocardiography for the diagnosis of pulmonary hypertension. Int J Cardiol 2018;263:177-83.

12. Jone PN, Ivy DD. Echocardiography in pediatric pulmonary hypertension. Front Pediatr 2014;2:124.

13. Jone PN, Ivy DD. Comprehensive Noninvasive Evaluation of Right Ventricle-Pulmonary Circulation Axis in Pediatric Patients with Pulmonary Hypertension. Curr Treat Options Cardiovasc Med 2019;21:6.

14. Koestenberger M, Friedberg MK, Nestaas E, et al. 
Transthoracic echocardiography in the evaluation of pediatric pulmonary hypertension and ventricular dysfunction. Pulm Circ 2016;6:15-29.

15. Ferrara F, Gargani L, Ostenfeld E, et al. Imaging the right heart pulmonary circulation unit: Insights from advanced ultrasound techniques. Echocardiography 2017;34:1216-31.

16. Jone PN, Patel SS, Cassidy C, et al. Three-dimensional Echocardiography of Right Ventricular Function Correlates with Severity of Pediatric Pulmonary Hypertension. Congenit Heart Dis 2016;11:562-9.

17. Jone PN, Schafer M, Pan Z, et al. 3D echocardiographic evaluation of right ventricular function and strain: a prognostic study in paediatric pulmonary hypertension. Eur Heart J Cardiovasc Imaging 2018;19:1026-33.

18. Cerro MJ, Abman S, Diaz G, et al. A consensus approach to the classification of pediatric pulmonary hypertensive vascular disease: Report from the PVRI Pediatric Taskforce, Panama 2011. Pulm Circ 2011;1:286-98.

19. Fisher MR, Forfia PR, Chamera E, et al. Accuracy of Doppler echocardiography in the hemodynamic assessment of pulmonary hypertension. Am J Respir Crit Care Med 2009;179:615-21.

20. Koestenberger M, Grangl G, Avian A, et al. Normal Reference Values and z Scores of the Pulmonary Artery Acceleration Time in Children and Its Importance for the Assessment of Pulmonary Hypertension. Circ Cardiovasc Imaging 2017. doi: 10.1161/CIRCIMAGING.116.005336.

21. Chemla D, Castelain V, Hoette S, et al. Strong linear relationship between heart rate and mean pulmonary artery pressure in exercising patients with severe precapillary pulmonary hypertension. Am J Physiol Heart Circ Physiol 2013;305:H769-77.

22. Chemla D, Castelain V, Provencher S, et al. Evaluation of various empirical formulas for estimating mean pulmonary artery pressure by using systolic pulmonary artery pressure in adults. Chest 2009;135:760-8.

23. Masuyama T, Kodama K, Kitabatake A, et al. Continuouswave Doppler echocardiographic detection of pulmonary regurgitation and its application to noninvasive estimation of pulmonary artery pressure. Circulation 1986;74:484-92.

24. Miller D, Farah MG, Liner A, et al. The relation between quantitative right ventricular ejection fraction and indices of tricuspid annular motion and myocardial performance. J Am Soc Echocardiogr 2004;17:443-7.

25. Koestenberger M, Nagel B, Avian A, et al. Systolic right ventricular function in children and young adults with pulmonary artery hypertension secondary to congenital heart disease and tetralogy of Fallot: tricuspid annular plane systolic excursion (TAPSE) and magnetic resonance imaging data. Congenit Heart Dis 2012;7:250-8.

26. Koestenberger M, Ravekes W, Everett AD, et al. Right ventricular function in infants, children and adolescents: reference values of the tricuspid annular plane systolic excursion (TAPSE) in 640 healthy patients and calculation of z score values. J Am Soc Echocardiogr 2009;22:715-9.

27. Lamia B, Teboul JL, Monnet X, et al. Relationship between the tricuspid annular plane systolic excursion and right and left ventricular function in critically ill patients. Intensive Care Med 2007;33:2143-9.

28. Forfia PR, Fisher MR, Mathai SC, et al. Tricuspid annular displacement predicts survival in pulmonary hypertension. Am J Respir Crit Care Med 2006;174:1034-41.

29. Bano M, Kanaan UB, Ehrlich AC, et al. Improvement in Tricuspid Annular Plane Systolic Excursion with Pulmonary Hypertension Therapy in Pediatric Patients. Echocardiography 2015;32:1228-32.

30. Eidem BW, McMahon CJ, Cohen RR, et al. Impact of cardiac growth on Doppler tissue imaging velocities: a study in healthy children. J Am Soc Echocardiogr 2004;17:212-21.

31. Burkett DA, Slorach C, Patel SS, et al. Impact of Pulmonary Hemodynamics and Ventricular Interdependence on Left Ventricular Diastolic Function in Children With Pulmonary Hypertension. Circ Cardiovasc Imaging 2016. doi: 10.1161/CIRCIMAGING.116.004612.

32. Koestenberger M, Nagel B, Ravekes W, et al. Tricuspid annular peak systolic velocity $\left(\mathrm{S}^{\prime}\right)$ in children and young adults with pulmonary artery hypertension secondary to congenital heart diseases, and in those with repaired tetralogy of Fallot: echocardiography and MRI data. J Am Soc Echocardiogr 2012;25:1041-9.

33. Takatsuki S, Nakayama T, Jone PN, et al. Tissue Doppler imaging predicts adverse outcome in children with idiopathic pulmonary arterial hypertension. J Pediatr 2012;161:1126-31.

34. Fenstad ER, Le RJ, Sinak LJ, et al. Pericardial effusions in pulmonary arterial hypertension: characteristics, prognosis, and role of drainage. Chest 2013;144:1530-8.

35. Shimony A, Fox BD, Langleben D, et al. Incidence and significance of pericardial effusion in patients with pulmonary arterial hypertension. Can J Cardiol 2013;29:678-82.

36. Di Maria MV, Younoszai AK, Mertens L, et al. RV stroke work in children with pulmonary arterial hypertension: estimation based on invasive haemodynamic assessment 
and correlation with outcomes. Heart 2014;100:1342-7.

37. Koestenberger M, Apitz C, Abdul-Khaliq H, et al. Transthoracic echocardiography for the evaluation of children and adolescents with suspected or confirmed pulmonary hypertension. Expert consensus statement on the diagnosis and treatment of paediatric pulmonary hypertension. The European Paediatric Pulmonary Vascular Disease Network, endorsed by ISHLT and D6PK. Heart 2016;102 Suppl 2:ii14-22.

38. Friedberg MK, Redington AN. Right versus left ventricular failure: differences, similarities, and interactions. Circulation 2014;129:1033-44.

39. Dufva MJ, Truong U, Tiwari P, et al. Left ventricular torsion rate and the relation to right ventricular function in pediatric pulmonary arterial hypertension. Pulm Circ 2018;8:2045894018791352.

40. Ghio S, Klersy C, Magrini G, et al. Prognostic relevance of the echocardiographic assessment of right ventricular function in patients with idiopathic pulmonary arterial hypertension. Int J Cardiol 2010;140:272-8.

41. McCrary AW, Malowitz JR, Hornick CP, et al.

Differences in Eccentricity Index and Systolic-Diastolic

Ratio in Extremely Low-Birth-Weight Infants with

Bronchopulmonary Dysplasia at Risk of Pulmonary

Hypertension. Am J Perinatol 2016;33:57-62.

42. Abraham S, Weismann CG. Left Ventricular EndSystolic Eccentricity Index for Assessment of Pulmonary Hypertension in Infants. Echocardiography 2016;33:910-5.

43. Burkett DA, Slorach C, Patel SS, et al. Left Ventricular Myocardial Function in Children With Pulmonary Hypertension: Relation to Right Ventricular Performance and Hemodynamics. Circ Cardiovasc Imaging 2015. doi: 10.1161/CIRCIMAGING.115.003260.

44. Hansmann G. Left Ventricular Diastolic Dysfunction in Pediatric Pulmonary Hypertension. Circ Cardiovasc Imaging 2016. doi: 10.1161/CIRCIMAGING.116.005527.

45. Nagueh SF, Smiseth OA, Appleton CP, et al.

Recommendations for the Evaluation of Left Ventricular Diastolic Function by Echocardiography: An Update from the American Society of Echocardiography and the European Association of Cardiovascular Imaging. J Am Soc Echocardiogr 2016;29:277-314.

46. Dragulescu A, Mertens L, Friedberg MK. Interpretation of left ventricular diastolic dysfunction in children with cardiomyopathy by echocardiography: problems and limitations. Circ Cardiovasc Imaging 2013;6:254-61.

47. Yared K, Noseworthy P, Weyman AE, et al. Pulmonary artery acceleration time provides an accurate estimate of systolic pulmonary arterial pressure during transthoracic echocardiography. J Am Soc Echocardiogr 2011;24:687-92.

48. Granstam SO, Bjorklund E, Wikstrom G, et al. Use of echocardiographic pulmonary acceleration time and estimated vascular resistance for the evaluation of possible pulmonary hypertension. Cardiovasc Ultrasound 2013;11:7.

49. Levy PT, Patel MD, Groh G, et al. Pulmonary Artery Acceleration Time Provides a Reliable Estimate of Invasive Pulmonary Hemodynamics in Children. J Am Soc Echocardiogr 2016;29:1056-65.

50. Habash S, Laser KT, Moosmann J, et al. Normal values of the pulmonary artery acceleration time (PAAT) and the right ventricular ejection time (RVET) in children and adolescents and the impact of the PAAT/RVETindex in the assessment of pulmonary hypertension. Int J Cardiovasc Imaging 2019;35:295-306.

51. Gaulton JS, Mercer-Rosa LM, Glatz AC, et al. Relationship between pulmonary artery acceleration time and pulmonary artery pressures in infants. Echocardiography 2019;36:1524-31.

52. Patel MD, Breatnach CR, James AT, et al. Echocardiographic Assessment of Right Ventricular Afterload in Preterm Infants: Maturational Patterns of Pulmonary Artery Acceleration Time Over the First Year of Age and Implications for Pulmonary Hypertension. J Am Soc Echocardiogr 2019;32:884-94.e4.

53. Koestenberger M, Avian A, Gamillscheg A, et al. Right ventricular base/apex ratio in the assessment of pediatric pulmonary arterial hypertension: Results from the European Pediatric Pulmonary Vascular Disease Network. Clin Cardiol 2018;41:1144-9.

54. Raza F, Dillane C, Mirza A, et al. Differences in right ventricular morphology, not function, indicate the nature of increased afterload in pulmonary hypertensive subjects with normal left ventricular function. Echocardiography 2017;34:1584-92.

55. Sarnari R, Kamal RY, Friedberg MK, et al. Doppler assessment of the ratio of the systolic to diastolic duration in normal children: relation to heart rate, age and body surface area. J Am Soc Echocardiogr 2009;22:928-32.

56. Alkon J, Humpl T, Manlhiot C, et al. Usefulness of the right ventricular systolic to diastolic duration ratio to predict functional capacity and survival in children with pulmonary arterial hypertension. Am J Cardiol 2010;106:430-6.

57. McCabe C, Vranesic II, Verdes MC, et al. Right 
ventricular systolic to diastolic duration ratio: A novel predictor of outcome in adult idiopathic pulmonary arterial hypertension. Int J Cardiol 2019;293:218-22.

58. Olsson KM, Nickel NP, Tongers J, et al. Atrial flutter and fibrillation in patients with pulmonary hypertension. Int J Cardiol 2013;167:2300-5.

59. Kumar S, Vadlamudi K, Kaddoura T, et al. Active right atrial emptying fraction predicts reduced survival and increased adverse events in childhood pulmonary arterial hypertension. Int J Cardiol 2018;271:306-11.

60. Jone PN, Schafer M, Li L, et al. Right Atrial Deformation in Predicting Outcomes in Pediatric Pulmonary Hypertension. Circ Cardiovasc Imaging 2017. doi: 10.1161/CIRCIMAGING.117.006250.

61. Ghio S, Pazzano AS, Klersy C, et al. Clinical and prognostic relevance of echocardiographic evaluation of right ventricular geometry in patients with idiopathic pulmonary arterial hypertension. Am J Cardiol 2011;107:628-32.

62. Koestenberger M, Sallmon H, Avian A, et al. Ventricularventricular interaction variables correlate with surrogate variables of clinical outcome in children with pulmonary hypertension. Pulm Circ 2019;9:2045894019854074.

63. Yung D, Widlitz AC, Rosenzweig EB, et al. Outcomes in children with idiopathic pulmonary arterial hypertension. Circulation 2004;110:660-5.

64. Jone PN, Hinzman J, Wagner BD, et al. Right ventricular to left ventricular diameter ratio at endsystole in evaluating outcomes in children with pulmonary hypertension. J Am Soc Echocardiogr 2014;27:172-8.

65. Zeng WJ, Sun YJ, Xiong CM, et al. Prognostic value of echocardiographic right/left ventricular enddiastolic diameter ratio in idiopathic pulmonary arterial hypertension. Chin Med J (Engl) 2011;124:1672-7.

66. Díaz-Gómez JL, Alvarez AB, Danaraj JJ, et al. A novel semiquantitative assessment of right ventricular systolic function with a modified subcostal echocardiographic view. Echocardiography 2017;34:44-52.

67. Kurath-Koller S, Avian A, Cantinotti M, et al. Normal Pediatric Values of the Subcostal Tricuspid Annular Plane Systolic Excursion (S-TAPSE) and Its Value in Pediatric Pulmonary Hypertension. Can J Cardiol 2019;35:899-906.

68. Lu X, Nadvoretskiy V, Bu L, et al. Accuracy and reproducibility of real-time three-dimensional echocardiography for assessment of right ventricular volumes and ejection fraction in children. J Am Soc Echocardiogr 2008;21:84-9.

69. Maffessanti F, Muraru D, Esposito R, et al. Age-, body size-, and sex-specific reference values for right ventricular volumes and ejection fraction by three-dimensional echocardiography: a multicenter echocardiographic study in 507 healthy volunteers. Circ Cardiovasc Imaging 2013;6:700-10.

70. Laser KT, Karabiyik A, Korperich H, et al. Validation and Reference Values for Three-Dimensional Echocardiographic Right Ventricular Volumetry in Children: A Multicenter Study. J Am Soc Echocardiogr 2018;31:1050-63.

71. Nagata Y, Wu VC, Kado Y, et al. Prognostic Value of Right Ventricular Ejection Fraction Assessed by Transthoracic 3D Echocardiography. Circ Cardiovasc Imaging 2017. doi: 10.1161/CIRCIMAGING.116.005384.

72. Jone PN, Schafer M, Pan Z, et al. Right VentricularArterial Coupling Ratio Derived From 3-Dimensional Echocardiography Predicts Outcomes in Pediatric Pulmonary Hypertension. Circ Cardiovasc Imaging 2019;12:e008176.

73. Levy PT, El-Khuffash A, Patel MD, et al. Maturational Patterns of Systolic Ventricular Deformation Mechanics by Two-Dimensional Speckle-Tracking Echocardiography in Preterm Infants over the First Year of Age. J Am Soc Echocardiogr 2017;30:685-98.e1.

74. Levy PT, Sanchez Mejia AA, Machefsky A, et al. Normal ranges of right ventricular systolic and diastolic strain measures in children: a systematic review and metaanalysis. J Am Soc Echocardiogr 2014;27:549-60, e3.

75. Morris DA, Krisper M, Nakatani S, et al. Normal range and usefulness of right ventricular systolic strain to detect subtle right ventricular systolic abnormalities in patients with heart failure: a multicentre study. Eur Heart J Cardiovasc Imaging 2017;18:212-23.

76. Li Y, Xie M, Wang X, et al. Right ventricular regional and global systolic function is diminished in patients with pulmonary arterial hypertension: a 2-dimensional ultrasound speckle tracking echocardiography study. Int J Cardiovasc Imaging 2013;29:545-51.

77. Fine NM, Chen L, Bastiansen PM, et al. Outcome prediction by quantitative right ventricular function assessment in 575 subjects evaluated for pulmonary hypertension. Circ Cardiovasc Imaging 2013;6:711-21.

78. Hardegree EL, Sachdev A, Villarraga HR, et al. Role of serial quantitative assessment of right ventricular function by strain in pulmonary arterial hypertension. Am J Cardiol 2013;111:143-8.

79. Driessen MMP, Meijboom FJ, Hui W, et al. Regional right ventricular remodeling and function in children with 
idiopathic pulmonary arterial hypertension vs those with pulmonary valve stenosis: Insights into mechanics of right ventricular dysfunction. Echocardiography 2017;34:888-97.

80. Vitarelli A, Mangieri E, Terzano C, et al. Threedimensional echocardiography and 2D-3D speckletracking imaging in chronic pulmonary hypertension: diagnostic accuracy in detecting hemodynamic signs of right ventricular (RV) failure. J Am Heart Assoc 2015;4:e001584.

81. Okumura K, Humpl T, Dragulescu A, et al. Longitudinal assessment of right ventricular myocardial strain in relation to transplant-free survival in children with idiopathic pulmonary hypertension. J Am Soc Echocardiogr 2014;27:1344-51.

82. Hopper RK, Wang Y, DeMatteo V, et al. Right ventricular function mirrors clinical improvement with use of prostacyclin analogues in pediatric pulmonary hypertension. Pulm Circ 2018;8:2045894018759247.

83. Hoeper MM, Bogaard HJ, Condliffe R, et al. Definitions and diagnosis of pulmonary hypertension. J Am Coll Cardiol 2013;62:D42-50.

84. D'Andrea A, Naeije R, D'Alto $M$, et al. Range in pulmonary artery systolic pressure among highly trained athletes. Chest 2011;139:788-94.

85. Argiento P, Vanderpool RR, Mule M, et al. Exercise stress echocardiography of the pulmonary circulation: limits of normal and sex differences. Chest 2012;142:1158-65.

86. El-Yafawi R, Rancourt D, Hacobian M, et al. Pulmonary hypertension subjects exhibit right ventricular transient exertional dilation during supine exercise stress echocardiography. Pulm Circ 2019;9:2045894019851904.

87. D'Alto M, Badagliacca R, Argiento P, et al. Risk Reduction and Right Heart Reverse Remodeling by Upfront Triple Combination Therapy in Pulmonary Arterial Hypertension. Chest 2020;157:376-83.

88. McLaughlin VV, Archer SL, Badesch DB, et al. ACCF/ AHA 2009 expert consensus document on pulmonary hypertension: a report of the American College of Cardiology Foundation Task Force on Expert Consensus Documents and the American Heart Association: developed in collaboration with the American College of Chest Physicians, American Thoracic Society, Inc., and the Pulmonary Hypertension Association. Circulation 2009;119:2250-94.

89. Latus H, Kuehne T, Beerbaum P, et al. Cardiac MR and CT imaging in children with suspected or confirmed pulmonary hypertension/pulmonary hypertensive vascular disease. Expert consensus statement on the diagnosis and treatment of paediatric pulmonary hypertension. The European Paediatric Pulmonary Vascular Disease Network, endorsed by ISHLT and DGPK. Heart 2016;102 Suppl 2:ii30-5.

90. Göransson C, Vejlstrup N, Scheike T, et al. Implications of cardiac variability with cardiovascular magnetic resonance imaging for calculating trial sample size in pulmonary arterial hypertension. Int J Cardiol 2018;257:332-8.

91. van Wolferen SA, Marcus JT, Boonstra A, et al. Prognostic value of right ventricular mass, volume, and function in idiopathic pulmonary arterial hypertension. Eur Heart J 2007;28:1250-7.

92. Grünig E, Peacock AJ. Imaging the heart in pulmonary hypertension: an update. Eur Respir Rev 2015;24:653-64.

93. Bradlow WM, Gibbs JS, Mohiaddin RH. Cardiovascular magnetic resonance in pulmonary hypertension. J Cardiovasc Magn Reson 2012;14:6.

94. Moledina S, Pandya B, Bartsota M, et al. Prognostic significance of cardiac magnetic resonance imaging in children with pulmonary hypertension. Circ Cardiovasc Imaging 2013;6:407-14.

95. van de Veerdonk MC, Kind T, Marcus JT, et al. Progressive right ventricular dysfunction in patients with pulmonary arterial hypertension responding to therapy. $\mathrm{J}$ Am Coll Cardiol 2011;58:2511-9.

96. Sanz J, Garcia-Alvarez A, Fernandez-Friera L, et al. Right ventriculo-arterial coupling in pulmonary hypertension: a magnetic resonance study. Heart 2012;98:238-43.

97. Truong U, Patel S, Kheyfets V, et al. Non-invasive determination by cardiovascular magnetic resonance of right ventricular-vascular coupling in children and adolescents with pulmonary hypertension. J Cardiovasc Magn Reson 2015;17:81.

98. Breeman KTN, Dufva M, Ploegstra MJ, et al. Right ventricular-vascular coupling ratio in pediatric pulmonary arterial hypertension: A comparison between cardiac magnetic resonance and right heart catheterization measurements. Int J Cardiol 2019;293:211-7.

99. Walsh MC, Szefler S, Davis J, et al. Summary proceedings from the bronchopulmonary dysplasia group. Pediatrics 2006;117:S52-6.

100.Vanderpool RR, Pinsky MR, Naeije R, et al. RVpulmonary arterial coupling predicts outcome in patients referred for pulmonary hypertension. Heart 2015;101:37-43.

101. Schuster A, Hor KN, Kowallick JT, et al. Cardiovascular Magnetic Resonance Myocardial Feature Tracking: Concepts and Clinical Applications. Circ Cardiovasc 
Imaging 2016;9:e004077.

102. Tello K, Dalmer A, Vanderpool R, et al. Cardiac Magnetic Resonance Imaging-Based Right Ventricular Strain Analysis for Assessment of Coupling and Diastolic Function in Pulmonary Hypertension. JACC Cardiovasc Imaging 2019;12:2155-64.

103.Lin ACW, Seale H, Hamilton-Craig C, et al. Quantification of biventricular strain and assessment of ventriculo-ventricular interaction in pulmonary arterial hypertension using exercise cardiac magnetic resonance imaging and myocardial feature tracking. J Magn Reson Imaging 2019;49:1427-36.

104. Mercurio V, Mukherjee M, Tedford RJ, et al. Improvement in Right Ventricular Strain with Ambrisentan and Tadalafil Upfront Therapy in Scleroderma-associated Pulmonary Arterial Hypertension. Am J Respir Crit Care Med 2018;197:388-91.

105. Sato T, Ambale-Venkatesh B, Lima JAC, et al. The impact of ambrisentan and tadalafil upfront combination therapy on cardiac function in scleroderma associated pulmonary arterial hypertension patients: cardiac magnetic resonance feature tracking study. Pulm Circ 2018;8:2045893217748307.

106. Ylänen K, Poutanen T, Savikurki-Heikkila P, et al. Cardiac magnetic resonance imaging in the evaluation of the late effects of anthracyclines among long-term survivors of childhood cancer. J Am Coll Cardiol 2013;61:1539-47.

107. Wang J, Zhao H, Wang Y, et al. Native T1 and T2 mapping by cardiovascular magnetic resonance imaging in pressure overloaded left and right heart diseases. J Thorac Dis 2018;10:2968-75.

108. Garcia J, Barker AJ, van Ooij P, et al. Assessment of altered three-dimensional blood characteristics in aortic disease by velocity distribution analysis. Magn Reson Med 2015;74:817-25.

109. Chen YY, Yun H, Jin H, et al. Association of native T1 times with biventricular function and hemodynamics in precapillary pulmonary hypertension. Int J Cardiovasc Imaging 2017;33:1179-89.

110. Roller FC, Wiedenroth C, Breithecker A, et al. Native T1 mapping and extracellular volume fraction measurement for assessment of right ventricular insertion point and septal fibrosis in chronic thromboembolic pulmonary hypertension. Eur Radiol 2017;27:1980-91.

111. Swift AJ, Rajaram S, Capener D, et al. LGE patterns in pulmonary hypertension do not impact overall mortality. JACC Cardiovasc Imaging 2014;7:1209-17.

112. Freed BH, Gomberg-Maitland M, Chandra S, et al.
Late gadolinium enhancement cardiovascular magnetic resonance predicts clinical worsening in patients with pulmonary hypertension. J Cardiovasc Magn Reson 2012;14:11.

113. Shehata ML, Lossnitzer D, Skrok J, et al. Myocardial delayed enhancement in pulmonary hypertension: pulmonary hemodynamics, right ventricular function, and remodeling. AJR Am J Roentgenol 2011;196:87-94.

114.Junqueira FP, Macedo R, Coutinho AC, et al. Myocardial delayed enhancement in patients with pulmonary hypertension and right ventricular failure: evaluation by cardiac MRI. Br J Radiol 2009;82:821-6.

115.McCann GP, Gan CT, Beek AM, et al. Extent of MRI delayed enhancement of myocardial mass is related to right ventricular dysfunction in pulmonary artery hypertension. AJR Am J Roentgenol 2007;188:349-55.

116. Abouelnour AE, Doyle M, Thompson DV, et al. Does Late Gadolinium Enhancement still have Value? Right Ventricular Internal Mechanical Work, Ea/Emax and Late Gadolinium Enhancement as Prognostic Markers in Patients with Advanced Pulmonary Hypertension via Cardiac MRI. Cardiol Res Cardiovasc Med 2017;2017.

117.Harloff A, Nussbaumer A, Bauer S, et al. In vivo assessment of wall shear stress in the atherosclerotic aorta using flow-sensitive 4D MRI. Magn Reson Med 2010;63:1529-36.

118. Schäfer M, Myers C, Brown RD, et al. Pulmonary Arterial Stiffness: Toward a New Paradigm in Pulmonary Arterial Hypertension Pathophysiology and Assessment. Curr Hypertens Rep 2016;18:4.

119. Dyverfeldt P, Bissell M, Barker AJ, et al. 4D flow cardiovascular magnetic resonance consensus statement. J Cardiovasc Magn Reson 2015;17:72.

120. Knobel Z, Kellenberger CJ, Kaiser T, et al. Geometry and dimensions of the pulmonary artery bifurcation in children and adolescents: assessment in vivo by contrast-enhanced MR-angiography. Int J Cardiovasc Imaging 2011;27:385-96.

121. Gan CT, Lankhaar JW, Westerhof N, et al. Noninvasively assessed pulmonary artery stiffness predicts mortality in pulmonary arterial hypertension. Chest 2007;132:1906-12.

122. Wentland AL, Grist TM, Wieben O. Review of MRIbased measurements of pulse wave velocity: a biomarker of arterial stiffness. Cardiovasc Diagn Ther 2014;4:193-206.

123. Friesen RM, Schafer M, Ivy DD, et al. Proximal pulmonary vascular stiffness as a prognostic factor in children with pulmonary arterial hypertension. Eur Heart J Cardiovasc Imaging 2019;20:209-17.

124. Bürk J, Blanke P, Stankovic Z, et al. Evaluation of 3D 
blood flow patterns and wall shear stress in the normal and dilated thoracic aorta using flow-sensitive 4D CMR. J Cardiovasc Magn Reson 2012;14:84.

125.Li M, Stenmark KR, Shandas R, et al. Effects of pathological flow on pulmonary artery endothelial production of vasoactive mediators and growth factors. J Vasc Res 2009;46:561-71.

126.Li M, Tan Y, Stenmark KR, et al. High Pulsatility Flow Induces Acute Endothelial Inflammation through Overpolarizing Cells to Activate NF-kappaB. Cardiovasc Eng Technol 2013;4:26-38.

127. Reiter G, Reiter U, Kovacs G, et al. Magnetic resonancederived 3-dimensional blood flow patterns in the main pulmonary artery as a marker of pulmonary hypertension and a measure of elevated mean pulmonary arterial pressure. Circ Cardiovasc Imaging 2008;1:23-30.

128. Schäfer M, Ivy DD, Abman SH, et al. Differences in pulmonary arterial flow hemodynamics between children and adults with pulmonary arterial hypertension as assessed by 4D-flow CMR studies. Am J Physiol Heart Circ Physiol 2019;316:H1091-H1104.

129. Schäfer M, Ivy DD, Barker AJ, et al. Characterization of CMR-derived haemodynamic data in children with pulmonary arterial hypertension. Eur Heart J Cardiovasc Imaging 2017;18:424-31.

130.Ku DN, Giddens DP, Zarins CK, et al. Pulsatile flow and atherosclerosis in the human carotid bifurcation. Positive correlation between plaque location and low oscillating shear stress. Arteriosclerosis 1985;5:293-302.

131.Pedrizzetti G, La Canna G, Alfieri O, et al. The vortex-an early predictor of cardiovascular outcome? Nat Rev Cardiol 2014;11:545-53.

132. Markl M, Schnell S, Barker AJ. 4D flow imaging: current status to future clinical applications. Curr Cardiol Rep 2014;16:481.

133. Schäfer M, Browning J, Schroeder JD, et al. Vorticity is a marker of diastolic ventricular interdependency in pulmonary hypertension. Pulm Circ 2016;6:46-54.

134. Schäfer M, Humphries S, Stenmark KR, et al. 4D-flow cardiac magnetic resonance-derived vorticity is sensitive marker of left ventricular diastolic dysfunction in patients with mild-to-moderate chronic obstructive pulmonary disease. Eur Heart J Cardiovasc Imaging 2018;19:415-24.

135.Fenster BE, Browning J, Schroeder JD, et al. Vorticity is a marker of right ventricular diastolic dysfunction. Am J Physiol Heart Circ Physiol 2015;309:H1087-93.

136. Kheyfets VO, Schafer M, Podgorski CA, et al. 4D magnetic resonance flow imaging for estimating pulmonary vascular resistance in pulmonary hypertension. J Magn Reson Imaging 2016;44:914-22.

137. Chen H, Xiang B, Zeng J, et al. The feasibility in estimating pulmonary vascular resistance by cardiovascular magnetic resonance in pulmonary hypertension: A systematic review and meta-analysis. Eur J Radiol 2019;114:137-45.

138. Göransson C, Vejlstrup N, Carlsen J. Exercise cardiovascular magnetic resonance imaging allows differentiation of low-risk pulmonary arterial hypertension. J Heart Lung Transplant 2019;38:627-35.

139. Fogel MA, Weinberg PM, Fellows KE, et al. A study in ventricular-ventricular interaction. Single right ventricles compared with systemic right ventricles in a dual-chamber circulation. Circulation 1995;92:219-30.

140. Damiano RJ Jr, La Follette P Jr, Cox JL, et al. Significant left ventricular contribution to right ventricular systolic function. Am J Physiol 1991;261:H1514-24.

141. Kallianos K, Brooks GC, Mukai K, et al. Cardiac Magnetic Resonance Evaluation of Left Ventricular Myocardial Strain in Pulmonary Hypertension. Acad Radiol 2018;25:129-35.

142. Göransson C, Vejlstrup N, Carlsen J. Reproducibility of peak filling and peak emptying rate determined by cardiovascular magnetic resonance imaging for assessment of biventricular systolic and diastolic dysfunction in patients with pulmonary arterial hypertension. Int J Cardiovasc Imaging 2018;34:777-86.

143. Schäfer M, Ivy DD, Abman SH, et al. Apparent Aortic Stiffness in Children With Pulmonary Arterial Hypertension: Existence of Vascular Interdependency? Circ Cardiovasc Imaging 2017. doi: 10.1161/ CIRCIMAGING.116.005817.

144. Sun Z, Choo GH, Ng KH. Coronary CT angiography: current status and continuing challenges. Br J Radiol 2012;85:495-510.

145. Aluja Jaramillo F, Gutierrez FR, Diaz Telli FG, et al. Approach to Pulmonary Hypertension: From CT to Clinical Diagnosis. Radiographics 2018;38:357-73.

146. Burghard P, Plank F, Beyer C, et al. Evaluation of right ventricular function by coronary computed tomography angiography using a novel automated $3 \mathrm{D}$ right ventricle volume segmentation approach: a validation study. Eur Radiol 2018;28:5129-36.

147. Baque-Juston MC, Wells AU, Hansell DM. Pericardial thickening or effusion in patients with pulmonary artery hypertension: a CT study. AJR Am J Roentgenol 1999;172:361-4. 
148. Worthy SA, Muller NL, Hartman TE, et al. Mosaic attenuation pattern on thin-section CT scans of the lung: differentiation among infiltrative lung, airway, and vascular diseases as a cause. Radiology 1997;205:465-70.

149. Tan RT, Kuzo R, Goodman LR, et al. Utility of CT scan evaluation for predicting pulmonary hypertension in patients with parenchymal lung disease. Medical College of Wisconsin Lung Transplant Group. Chest 1998;113:1250-6.

150.Ng CS, Wells AU, Padley SP. A CT sign of chronic pulmonary arterial hypertension: the ratio of main pulmonary artery to aortic diameter. J Thorac Imaging 1999;14:270-8.

151. Wells JM, Washko GR, Han MK, et al. Pulmonary arterial enlargement and acute exacerbations of COPD. N Engl J Med 2012;367:913-21.

152.Fu H, Wang X, Diao K, et al. CT compared to MRI for functional evaluation of the right ventricle: a systematic review and meta-analysis. Eur Radiol 2019;29:6816-28.

Cite this article as: Truong $\mathrm{U}$, Meinel K, Haddad F, Koestenberger M, Carlsen J, Ivy D, Jone PN. Update on noninvasive imaging of right ventricle dysfunction in pulmonary hypertension. Cardiovasc Diagn Ther 2020;10(5):1604-1624. doi: $10.21037 /$ cdt-20-272
153. Guo XJ, Liu MX, Ma ZH, et al. Assessing right ventricular function in patients with pulmonary artery hypertension based on noninvasive measurements: correlation between cardiac MRI, ultrasonic cardiogram, multidetector CT and right heart catheterization. Zhonghua Yi Xue Za Zhi 2018;98:3528-31.

154. Rajaram S, Swift AJ, Capener D, et al. Comparison of the diagnostic utility of cardiac magnetic resonance imaging, computed tomography, and echocardiography in assessment of suspected pulmonary arterial hypertension in patients with connective tissue disease. J Rheumatol 2012;39:1265-74.

155.Mazraeshahi RM, Striet J, Oeltgen RC, et al. Myocardial SPECT images for diagnosis of pulmonary hypertension and right ventricular hypertrophy. J Nucl Med Technol 2010;38:175-80.

156. Cohen HA, Baird MG, Rouleau JR, et al. Thallium 201 myocardial imaging in patients with pulmonary hypertension. Circulation 1976;54:790-5. 